Florida International University FIU Digital Commons

2-4-2011

\title{
An Analysis Of Five Compositions Representing The Fusion Of Jazz, World, and Latin American Rhythms
}

Hector D. Neciosup

Florida International University, hnmusicfl@gmail.com

DOI: $10.25148 /$ etd.FI1 1041502

Follow this and additional works at: https://digitalcommons.fiu.edu/etd

\section{Recommended Citation}

Neciosup, Hector D., "An Analysis Of Five Compositions Representing The Fusion Of Jazz, World, and Latin American Rhythms" (2011). FIU Electronic Theses and Dissertations. 341.

https://digitalcommons.fiu.edu/etd/341 


\section{FLORIDA INTERNATIONAL UNIVERSITY}

Miami, Florida

AN ANALYSIS OF FIVE COMPOSITIONS REPRESENTING THE FUSION OF JAZZ, WORLD, AND LATIN AMERICAN RHYTHMS

A thesis submitted in partial fulfillment of the

requirements for the degree of

MASTER OF MUSIC

by

Hector Neciosup

2011 
To: Dean Brian Schriner

College of Architecture and the Arts

This thesis, written by Hector Neciosup, and entitled An Analysis of Five Compositions Representing the Fusion of Jazz, World, and Latin American Rhythms, having been approved in respect to style and intellectual content, is referred to you for judgment.

We have read this thesis and recommend that it be approved.

Karen Fuller

Mike Orta

Gary Campbell, Major Professor

Date of Defense: February 4, 2011

The thesis of Hector Neciosup is approved.

\begin{tabular}{c} 
Dean Brian Schriner \\
College of Architecture and the Arts \\
\hline Interim Dean Kevin O'Shea \\
University Graduate School
\end{tabular}

Florida International University, 2011 


\section{ACKNOWLEDGMENTS}

I want to thank my wife and my mother for their continued support; my daughters because they keep me dreaming towards the future; my uncle Alex Acuna, a great inspiration to my musical abilities; and my students because they keep my candlelight burning. Above all, I want to thank my Lord and Savior Jesus Christ for giving me a new life full of blessings that help my musical creativity. 
ABSTRACT OF THE THESIS

AN ANALYSIS OF FIVE COMPOSITIONS REPRESENTING THE FUSION OF

JAZZ, WORLD, AND LATIN AMERICAN RHYTHMS

\author{
by \\ Hector Neciosup \\ Florida International University, 2011 \\ Miami, Florida \\ Professor Gary Campbell, Major Professor
}

The purpose of this Thesis Recital, documented on the accompanying compact disc, was to merge the influences of American Jazz, World Music, and Latin American idioms into a program of five original arrangements for six-piece band. Each arrangement combines a modern approach to jazz harmony and melody with world percussion rhythms and instruments. Rhythms from different parts of the world are integrated, creating a special, completely innovative blend. The instrumentation I have chosen — together with the stylistic contributions of the individual performers — create a sound, and timbre that combines influences from Rock, Jazz, Latin, and World music. The instrumentation consists of electric guitar, trumpet, piano/keyboard, electric/acoustic bass, percussion, and drums/percussion. The following pages will analyze each piece, with special attention to the mixture of musical elements that create this unique style of arranging, composition, and performance. An appendix provides scores of my five arrangements. 


\section{TABLE OF CONTENTS}

CHAPTER

PAGE

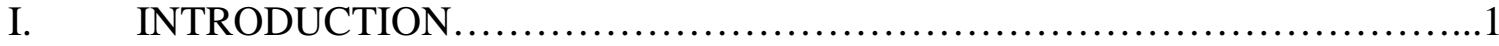

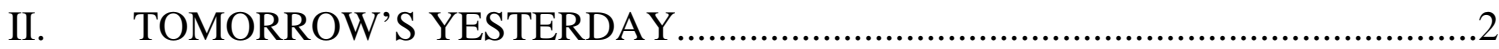

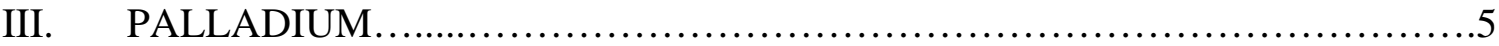

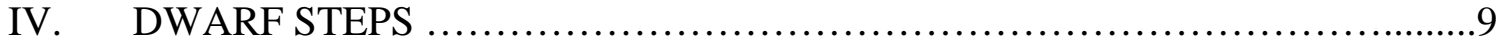

V. $\quad$ SUNSET DANCING ............................................................

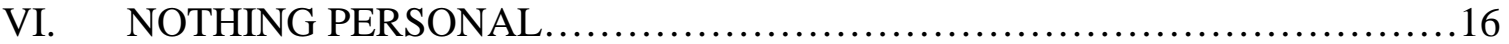

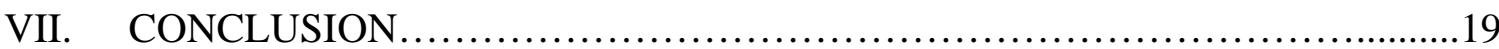

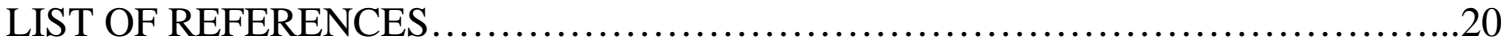

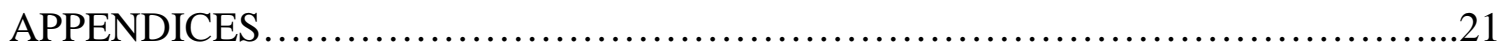




\section{LIST OF EXAMPLES}

EXAMPLE

PAGE

1. Tomorrow’s Yesterday Rhythmic Pattern of the A section.........................

2. Tomorrow’s Yesterday Harmonic Pattern of a B section............................4

3. Palladium Opening Melodic Pattern..........................................6

4. Palladium Son \& Rumba Clave.................................................

5. Palladium Bass Guitar Pattern...............................................8

6. Dwarf Steps Melody Pattern of the A section...................................10

7. Sunset Dancing Melodic, Harmonic, \& Rhythmic Patterns of the B section...............14

8. Sunset Dancing Tutti Break................................................15

9. Sunset Dancing Odd Time Meters..........................................16

10. Nothing Personal Drum Set Pattern........................................17

11. Nothing Personal Cajon Pattern.............................................

12. Nothing Personal Guitar \& Bass Pattern.....................................18 


\section{INTRODUCTION}

This paper consists of five pieces. Two are rearrangements of jazz standards, and the other three are my arrangements of more recent compositions by Paul Banman and Carlos Puig. The two standards are by the famous jazz composers Wayne Shorter and Don Grolnick. Shorter’s tune “Palladium,” recorded in 1977, blended son, a Cuban music style, and funk, a rhythm-driven genre of American Pop music. This blend influenced my performance and writing. In "Palladium" an active bass line interacts with a broad, syncopated melody scored for keyboard/synthesizer, electric guitar, and trumpet—an unusual but effective combination.

Grolnick’s piece "Nothing Personal” shows the harmonic influence of a minor blues expanded to twenty-four bars. It has a fast bebop line with some pauses for rhythm section fills. The solos section changes from festejo, an afro-Peruvian rhythm, to straight ahead swing. The addition of the festejo rhythm creates a pleasant blend of jazz, funk, and Afro-Peruvian.

“Dwarf Steps” composed by Carlos Puig, is an original Latin jazz composition. The melody and solos are developed in a swing style, emulating as much as possible the character of Coltrane's famous 1960 solo for Giant Steps. The melodic shape of this composition follows patterns to be found in the music of other Cuban jazz groups like Irakere, Afro Cuba, and los Van Van. The melody is created through the use of syncopated accents and the contour of the arpeggio. The drum set rhythm has the cascara

ride pattern, which is an authentic Afro-Cuban rhythm, and the clave concept, a five-note pattern that establishes all Afro-Cuban rhythms. 
The next piece "Sunset Dancing," composed by Paul Banman, was inspired by Chick Corea's style, of a jazz tune that exploits the samba, a rhythm from Rio de Janeiro, and the batucada, a Brazilian rhythm in which many drums play together. This composition has a descending, chromatic, and a syncopated melody line in one section and static whole notes on the other. The harmony moves chromatically, in ii-V sequences over with pedal tones. The form ends with changes of time signatures at the coda.

The next piece "Tomorrow and Yesterday" is also composed by Paul Banman, which I have added the drum and percussion parts. The melody is free from the constraints of a preconceived harmonic scheme. The B section uses power chords. The rhythms are African and Afro-Peruvian: Yeza, a religious African rhythm and Panalivio, an Afro-Peruvian rhythm. The primary instruments used are the cajon, batas, and tumbadora, all hand drum instruments. The drum set and power chords contribute an aggressive rock style, while the syncopated melody and bebop line lend the piece elements of the swing style. The solo sections are played in a swing style. All of these elements—bebop melodies, jazz chords, and mixture of rhythms from different parts of the world, alongside the professional cohesion of the group—create an organized novel fusion.

\section{TOMORROW'S YESTERDAY}

“Tomorrow’s Yesterday” is a composition written by Paul Banman, which I have added the drum and percussion parts.

The form of the song is as follows:

$$
\text { A (12 mm.) A (12 mm.) B (8 mm.) B (8 mm.). }
$$


The solos section follows a different format that will be explained later. The song starts with an open percussion ensemble combining the Iyesá (sometimes pronounced Yesá), an African rhythm, and the Panalivio, which is an Afro-Peruvian rhythm. The batá drums, African hand drums, congas and cajón (a rectangular box with a hole in the back) establish the tempo. The cajon is played by sitting on top of it and hitting it with the palms of the hands. This instrument produces a variety of timbres. ${ }^{1}$ These hand percussion instruments along with the American drum set are the primary percussion instruments used. The rhythm used is as follows:

Example 1 Tomorrow's Yesterday Rhythmic pattern of the A section.

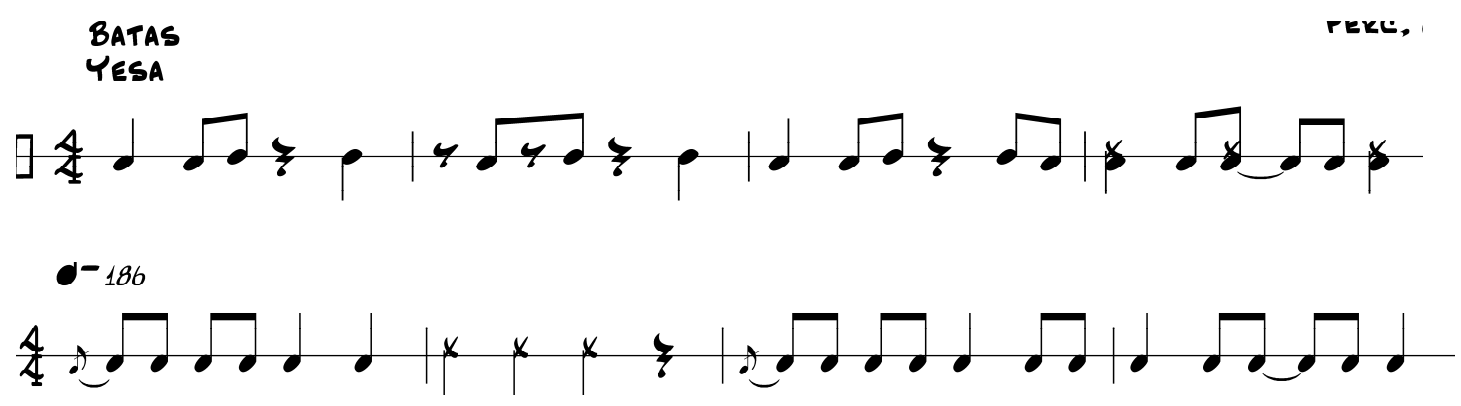

Right after the tempo has been established, there is an eight-bar swing/rock vamp that leads into the melody with a swing feel. The melody enters with a chromatic bebop line played in unison by the guitar, trumpet and keyboard, with background accentuated hits in the bass guitar, drums, and percussion. The repeat of the "A" section finishes with a different chord, a Bb6/9 to prepare the forceful "B" section. The "B" section has an energetic Rock feel that provides a release from the edgy melodic chromaticism and rhythmic surprises of the " $\mathrm{A}$ " section, while maintaining the intensity and energy of the piece with a driving groove, polychords, and ostinato type bass.

\footnotetext{
${ }^{1}$ For more on Cajon see Feldman, 2009, 26
} 
The harmonic progression of the "B" section rock section follows the $\mathrm{I}-\mathrm{V}-\mathrm{VI}$ progression without the thirds where the electric guitar and bass accompany with some power chords. The melody has an arpeggiated descending line, and the percussion adds the Iyesa and Panalivio rhythm, again creating an intense African Rock fusion section. The harmonic progression for the rock section is as follows:

Example 2 Tomorrow’s Yesterday Harmonic pattern of the B section.

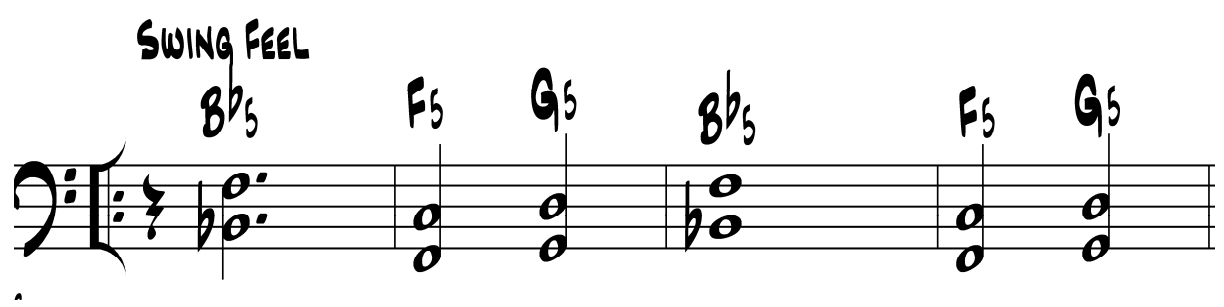

After the head is played twice, the solo section starts. Creating a forum for improvisation, the solo "A" section provides a strong connection to the head "A" section, while allowing the soloist plenty of room for self-expression. The solo "B" section has the African Rock fusion background that helps the soloist be creative, who plays over the rhythm section groove and ostinato bass. Later in the piece this section gives the drummer and percussionists a chance to solo and play off the repetitive accent pattern of the ostinato. The solo section with its straight-ahead jazz feel, consists in a pattern chord changes that the soloist can elaborate upon, finishing with a four-measure repeated figure in an African Rock style. All solos follow the same format. After the last solo during the African Rock section the percussionists trade eight-bar measures solo with the drummer. Then the keyboard plays a cue melody line that indicates to go back to Da Capo. Finally, the head is played one time and then the coda. The coda finishes with three half notes 
ritardando using the Bb5, F5, G5 power chords, sustaining and resolving the last chord from a Dsus to a D3/4.

\section{PALLADIUM}

The second song "Palladium," was recorded in 1977 by Weather Report and arranged by Wayne Shorter. This group changed history in the jazz realm. The combination of sounds, grooves, rhythms, and creativity when soloing made them unique. Even though Shorter wrote this tune, his colleagues contributed to his arrangement. For example, Joe Zawinul, keyboard player of Weather Report applies a Latin Funk groove with a back-beat on the snare drum. He uses the electric piano during the melodies to create a specific sound. Zawinul mentions that he likes the strong approach to jazz and not lightweight stuff. ${ }^{2}$ This approach can be heard in this composition.

I re-arranged "Palladium" faster than the original recording, but without losing the fundamental nature of the composition. It starts with a Rumba Clave break; which is a 5 note pattern that repeats twice by the percussion ensemble. Then, there is a unison line playing tutti (by everyone). This line is in fortissimo dynamic level, it creates suspense and climax from the beginning of the song. The line goes as follows:

\footnotetext{
${ }^{2}$ Jazz Rock, see Nicholson 1998, 163.
} 


\section{Example 3 Palladium Opening Melodic Pattern}

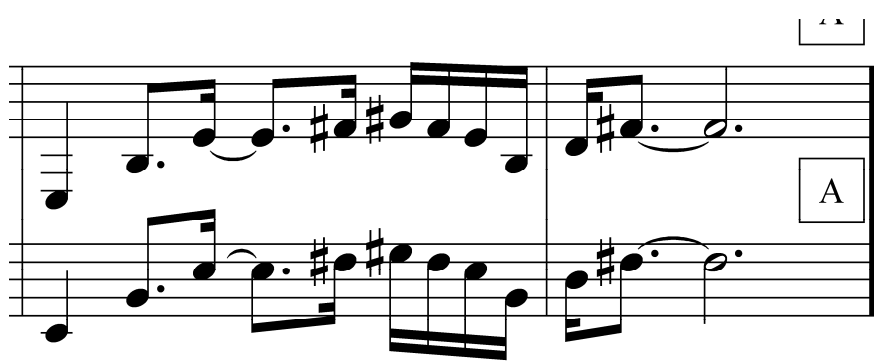

The fusion of rhythms I use are the Latin Funk and the Songo, which is an AfroCuban rhythm created by Juan Formell, band leader of the famous Cuban group los Van Van, who "incorporated into the basics of the son rhythmic elements that he borrowed from the music of other countries." ${ }^{3}$ The theory of the clave has to be understood before one writes or plays an arrangement in this style." The clave means "key" in Spanish and this is precisely what the clave rhythm is; it is the rhythmic key and fundamental building block of all the Afro Cuban song styles ${ }^{4}$. Its influence can be found in all music that has the touch of African culture. In Afro-Cuban music, there are two different clave rhythms, the Son Clave, which is the most played clave on all commercial Latin music and Rumba Clave, which is used for the folklore Rumba Styles and other rhythms ${ }^{5}$. This song starts with the 3-2 Rumba clave break, which has a small variation from the Son clave on the $4^{\text {th }}$ beat. Every Latin arranger knows that the clave is the most important element when writing Latin music. Originally the clave was created to play in cut time, in this rearrangement the clave is written in 4/4 time signature; therefore, all phrases fit in one measure. The clave is a two bar phrase with three notes in one bar and two in the other.

\footnotetext{
${ }^{3}$ Cuban Music, see Roy 2002, 159-160.

${ }^{4}$ See Uribe 1996, 34

${ }^{5}$ See Uribe 1996, 96
} 
Both claves are illustrated as follows:

Example 4 Palladium Son \& Rumba Clave

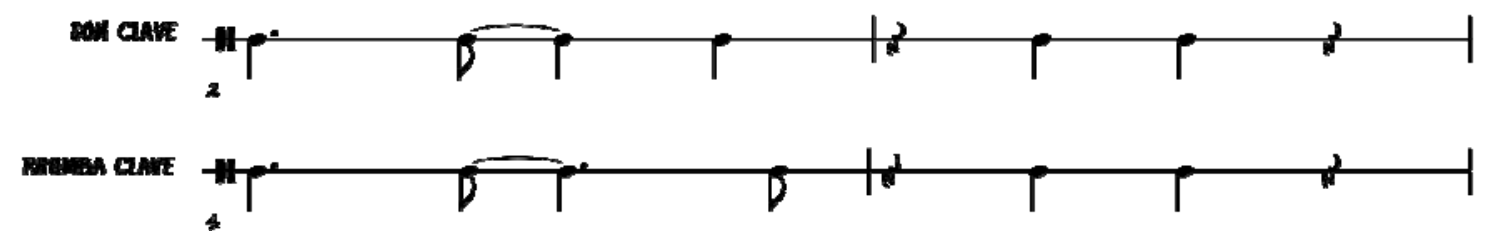

This tells us which bar will be the starting point of the two bar phrase. Since this tune is re-written in $4 / 4$ the phrases will always be one measure long, but still causes it to establish a pattern of a call and response. The melodic and rhythmic phrases played by most of the instrumentalists are always following the clave ostinato. The reason why the clave is explained at this point is because every pattern played by the drums, percussion, and bass guitar follow the clave pattern throughout the song, even though no one is playing a strict clave, it is felt. The bass player plays a funk groove mixed with timba, which is an offspring of the songo rhythm, and this phrase is based on the clave. The songo rhythms played by the percussionists are also based on the clave.

After the rumba clave and the tutti section are played, the "A" section starts. Palladium has an A B C form structure but the solos are over an eight-bar repeated phrase. The "A" section melody has some hits based on polychords in which the drummer fills in throughout all rests and prepares every hit. Half way through the "A" section the bass guitar comes in with a percolating pattern, that has a continuous activity and movement that carries the whole tune. This bass line emphasizes the 3-2 Rumba clave. The bass line is as follows: 


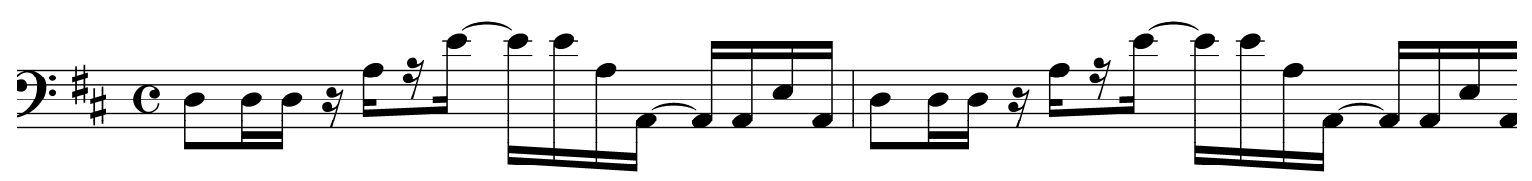

The harmonic movement of the " $\mathrm{B}$ " section is a ii-V-I progression. In this section the trumpet and synthesizer play the melody and the electric guitar joins it at the end of the phrases. The left hand of the piano accompaniment imitates the traditional jazz comp, leaving spaces. Once in while the piano plays the tumbao, which is an authentic busy piano accompaniment for Latin music, leaving enough space for the rhythm section to fill in. The group creates a blend of sounds maintaining the jazz idiom and keeping the Latin funk groove that drives.

The "C" section goes to a fortissimo dynamic level where the guitar semiimprovises, plays lead notes, and uses distortion to give an aggressive rock ambience. The drum set plays lots of cymbals and crashes to support it. The percussion ensemble, bongos, and accessories play the groove, but the congas improvise a little without loosing the groove. The piano fills in with subtle notes. This "C" section has lots of colors, is open and mostly improvised. It is based on a F9 Suspended chord. Every musician adds something without being in each other's way.

Following, the second time at “A” there is an idea created by Shorter, which was the omission of measures that surprises the listener but creates an interesting change in the structure of the song. Lastly, the solo section starts with a repeated eight-bar melody played by the trumpet, keyboard, and guitar. It follows with a trade-eighth solo section played three times among the electric guitar, keyboard, and trumpet. Finally, this solo 
section culminates with a drum set and percussion sixteenth-measure trade before going to Da Capo. And finally, the song ends on the ninth bar of "A."

\section{DWARF STEPS}

The next song is "Dwarf Steps" written by Carlos Puig-Hatem, and I added the percussion and drum set parts. It is an instrumental Latin jazz song conceived as a tribute to the great jazz musician, John Coltrane, as it is based on his 1960 ground-breaking composition "Giant Steps." The structure is an ABA1 form. The objective of the piece was to pay homage to Coltrane by crafting an original composition firmly based upon the "Giant Steps" harmonic discoveries and contributions to the jazz language. In those terms, "Dwarf Steps" could be considered as an imitation or oxymoronically a "serious parody" (if such a contradiction were possible!) Even today, Coltrane's composition remains within the limits of a "serious" line of jazz crafted to be listened and appreciated for its full worth. "Dwarf Steps" hopes to mirror that character. Even though "Dwarf Steps” is being performed as a Latin jazz song, the melody and solos are developed in a swing style, emulating as much as possible the character of Coltrane's ultra-famous 1960 solo for Giant Steps.

On the other hand, the Latin character of the piece could be framed in the Cuban jazz tradition. The drum pattern follows the cascara pattern with open hi hats, the congas play the songo pattern with variations, and the timbales follow the son montuno, guaracha, and songo style, these are all Afro-Cuban rhythms. The melodic shape of this composition follows certain patterns to be found in other recent Cuban jazz recordings 
used by groups like Irakere, Afro Cuba, and Los Van Van. Through the presence of syncopated accents, the contour of the arpeggio-based melody is given a vivid character. The melody goes as follows:

Example 6 Dwarf Steps Melody Pattern of the A section.

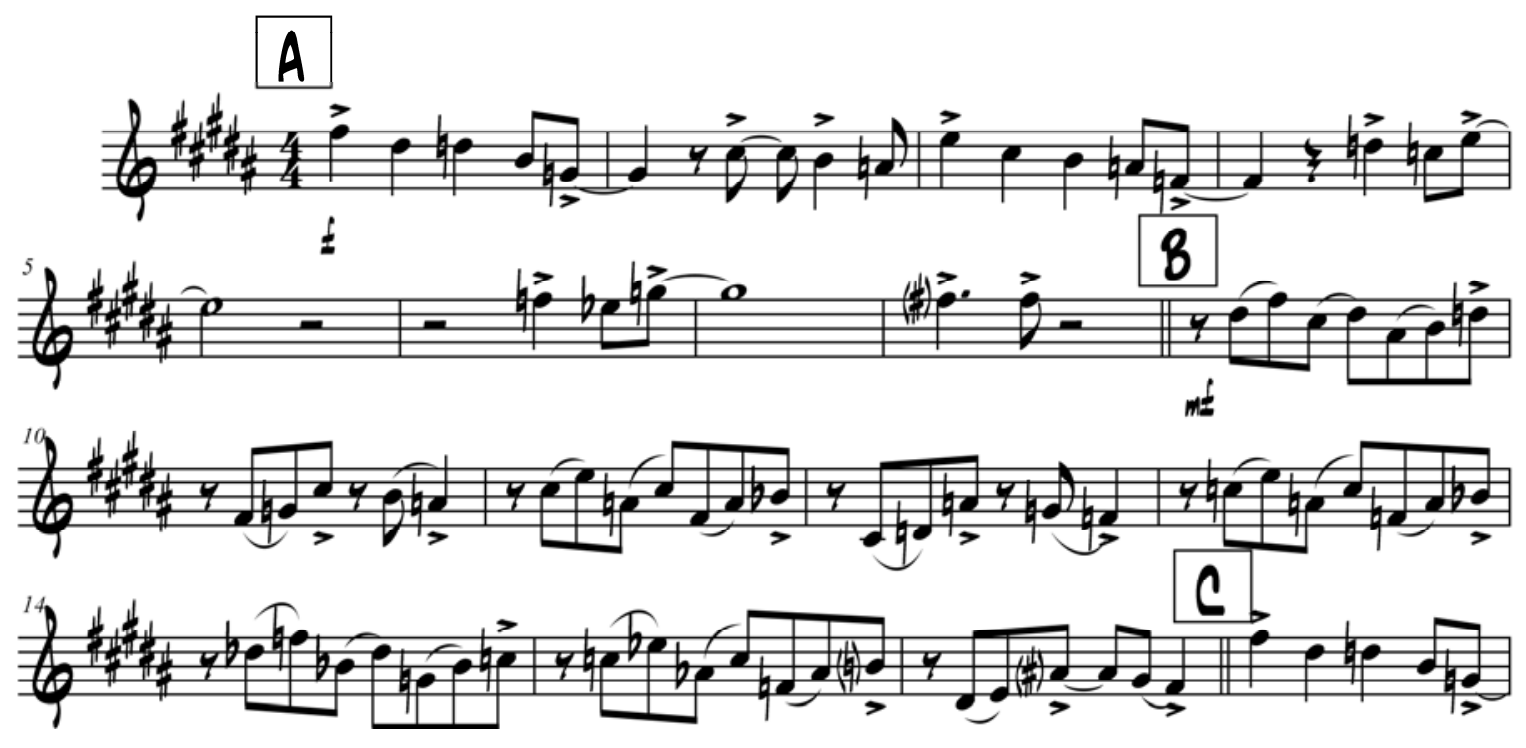

The specific way "Dwarf Steps” was based upon “Giant Steps” was by doing just the opposite of what Coltrane did in his composition in terms of harmonic progression and melodic construction. The goal was to "size down" these elements as follows: first, "Giant Steps" harmonic cycle uses a progression based on the division of the octave in three equal parts. Altogether, the three resulting tones constitute an augmented triad. "Dwarf Steps" divides the octave in four equal parts, which results in four tones constituting a diminished seven chord. Second, “Giant Steps" harmonic sequence goes from B major to E flat and G major, and finishes returning to B major. All those keys are a major 3rd apart from one another. "Dwarf Steps" modulates from B major to D, F and Ab, all a minor 3rd apart. 
Third, "Giant Steps” progression begins with an ascending interval of minor 3rd, B to D, first of a chord progression which ends up in Eb, a major 3rd apart. "Dwarf Steps” progression begins with a descending major 3rd, B to G, leading to D, a minor 3rd apart. Fourth, "Giant Steps” melody presents one note per chord, while "Dwarf Steps" presents two notes per change. The rhythmic values were diminished (canonic technique) to their half time/value. This causes the Dwarf Steps' harmonic cycle to be shorter than Coltrane's, which explains why it was necessary to introduce a bridge section containing a second melody in order to "complete" the number of measures of the original harmonic progression. Fifth, Giant Steps' melody begins with an interval of major 3rd, while Dwarf Steps' begins with a minor 3rd.

\section{Tonal Centers 1:}

Giant Steps: B-Eb-G (augmented triad) a major third apart

Dwarf Steps: B-D-F-Ab (diminished seven chord) a minor third apart

2: Harmonic Progression Patterns

Giant Steps: Bmaj-D7-Gmaj-Bb7-Ebmaj

Dwarf Steps: Bmaj-Gmaj-Emin7-A7-Dmaj

The next example illustrates the complete harmonic cycle for each song.

3: Complete Harmonic Progression of Both Songs.

Giant Steps:

Bmaj-D7-Gmaj-Bb7-Ebmaj/ Amin7-D7/ Gmaj-Bb7-Ebmaj-F\#7-Bmaj /

Fmin7-Bb7-Ebmaj/ Amin7-D7-Gmaj/ C\#min7-F\#7-Bmaj/ Fmin7-Bb7 -

Ebmaj/ C\#min7-F\#7 //

Dwarf Steps: 


\section{Bmaj-Gmaj-Emin7-A7-Dmaj/ Gmin7-C7/ Fmaj-Dbmaj-Bbmin7-Eb7-Abmaj/ \\ C\#min7-F\#7-Bmaj/ Emin7-A7-Dmaj/ Gmin7-C7-Fmaj/ Bbmin7-Eb7-Abmaj/ \\ C\#min7-F\#7 //}

The solos follow this order: the guitar first, piano second, trumpet third, and last there is a eight-measure trade with drums. Each instrumentalist solos during the A and B section of the song. The drum set and percussion solo trade is on the A section only. After all solos, the head melody is played one time and fine. This song is a good example of the harmonic cycle progression helping create a pleasant melodic line, considering the swing style, and allows the rhythm section to keep a soft Latin groove. Usually AfroCuban rhythms are loud and energetic. This composition is lighter, taking into consideration the straight ahead jazz sound.

\section{V: SUNSET DANCING}

The next original song "Sunset Dancing” was composed by Paul Banmam, I added the drum and percussion parts. It is a Chick Corea inspired samba jazz tune in an ABAC form, and starts with six measure of a traditional Samba percussion break that leads into the melody. The rhythms used are the Samba, which comes from Angola and has the connotation of the "invitation to the dance." This rhythm was used when the slaves got together for a party. ${ }^{6}$ This is the most popular rhythm from Brazil and is usually played in 2/4 time signature, but in this arrangement is written in 4/4 to fit the

\footnotetext{
${ }^{6}$ For more on samba see McGowan and Pessanha 2009, 19
} 
melody and composition ideas. The other rhythm used in the "B" section is the Batucada, which is another type of Samba. "The word Batucada means many drums playing together, it comes from the African rhythm batuque," which means let's play drums. ${ }^{7}$

The melody starts with a syncopated chromatic line in unison played by the guitar and keyboard. The rhythm section starts the "A" section with a stop on the down beat of one and continues on the third beat playing the samba groove, creating a contemporary style of Brazilian-Latin music writing, in which the rhythm section stops in the middle of the melody, then continues, creating a pause, something unexpected that surprises the listener. The "A" section builds with a harmonic chromatic half step motions, going from an Abmaj7b5 to A minor, follow by a B diminished 7th to C minor chord. Then it moves to an ii-V harmonic progression, $\mathrm{Bb}$ minor to an Eb7 and Eb minor to an Ab7\#1, then continues the same harmonic pattern but a half step down. The dynamic level of the "A" section is mezzo forte.

The " $\mathrm{B}$ " section increases to a forte volume creating a contrast to the " $\mathrm{A}$ " section. The drum set, percussion instruments and the electric bass accompanies with an authentic batucada rhythm. This "B" section has a motionless whole note melody. There is a contrast between the melody and the rhythm. The melody is a four-bar phrase that carries a static whole note line for three measures; it finishes on the third beat of the fourth measure with a half note. On the contrary, the percussion ensemble plays the batucada rhythm, which is busy and loud. In Brazilian music it is very common to start a phrase on the fourth beat of the measure. The repeat to the " $\mathrm{A}$ " section starts with a pick up quarter note on the fourth beat of the last measure of "B." The second time at "A" the guitar is

\footnotetext{
${ }^{7}$ See Moura 2007, 38
} 
tacit and the trumpet doubles the melody with the keyboard to create a different sound the when playing the melody.

The following musical illustration shows the ending of the " $\mathrm{B}$ " section how rhythm section finishes on the third beat with the pick up on the fourth beat to go back to “A.” Also, illustrated is the $2^{\text {nd }}$ ending where the pedal tones F\# and D is sustained, that will be explain later:

Example 7 Sunset Dancing Melodic, Harmonic, \& Rhythmic Patterns of the B section
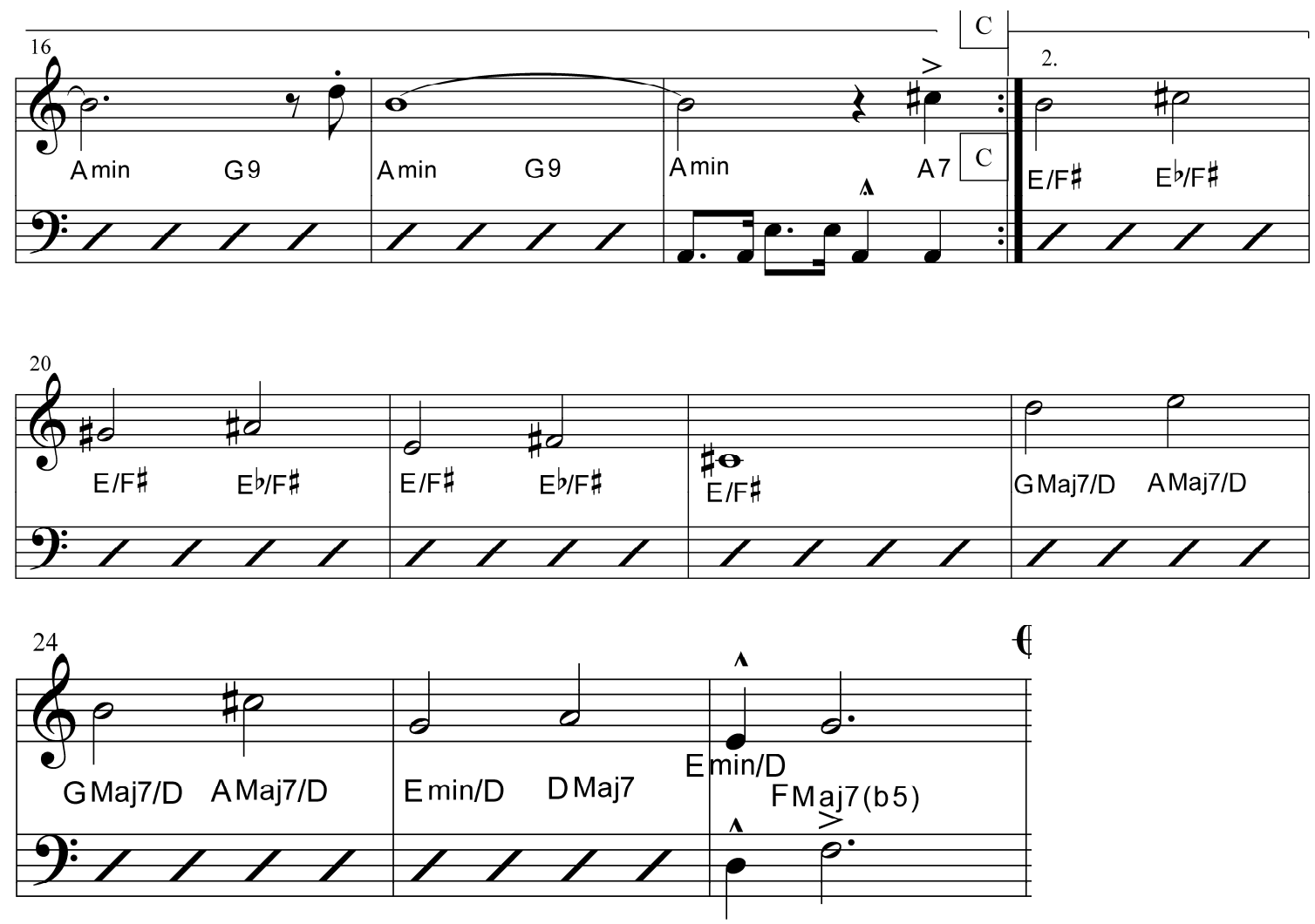

After the "A" section is played twice, the "C" section follows a harmonic progression using 2 pedal bass notes F\# and D. Pedal tones give a sense of suspense that it needs to be resolved. The ascending whole steps movement melody and the harmonic progression played in this section create just that. And it gives space for the percussion 
ensemble to play busier; this is where the batucada rhythm is played again. This section is an eight-measure phrase with an added break measure. The eighth measure has an accented quarter note on the down beat and a dotted half note on the second beat that prepares percussion break. The unison percussion break is an added measure that cues back to the melody and later to the solos. This break is important because it cues all the solos and gives the composer the idea for the coda.

Example 8 Sunset Dancing Tutti Break

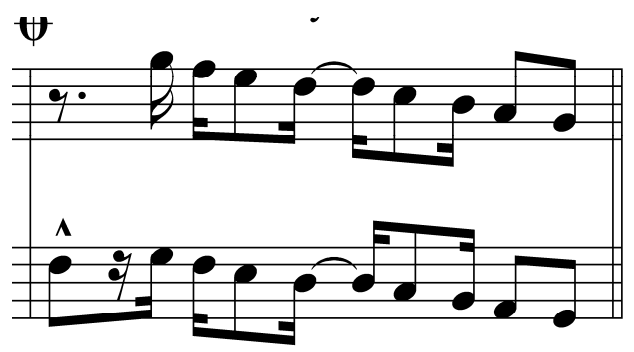

The structure for solos is the same as the head form - ABAC. At the beginning of each the solos the rhythm section stops on the down beat of the first measure, rests on the second, and continues on the third beat, repeating the same idea used in the melody. The "A" section challenges the soloist to find creative ways to connect the chord changes, while the "B" section open and suspense allow for more solo freedom and interaction between the soloist and the rhythm section. After the last instrumental solo, there is an eight-bar drum and percussion solo before a recapitulation of the head leading to the coda. Finally the coda is a dynamic extended unison rhythm ending with meter changes, from a $4 / 4$ to a $3 / 4$ to a $2 / 4$ and two measures of $4 / 4$. They look as follows: 
Example 9 Sunset Dancing Odd Time Meters
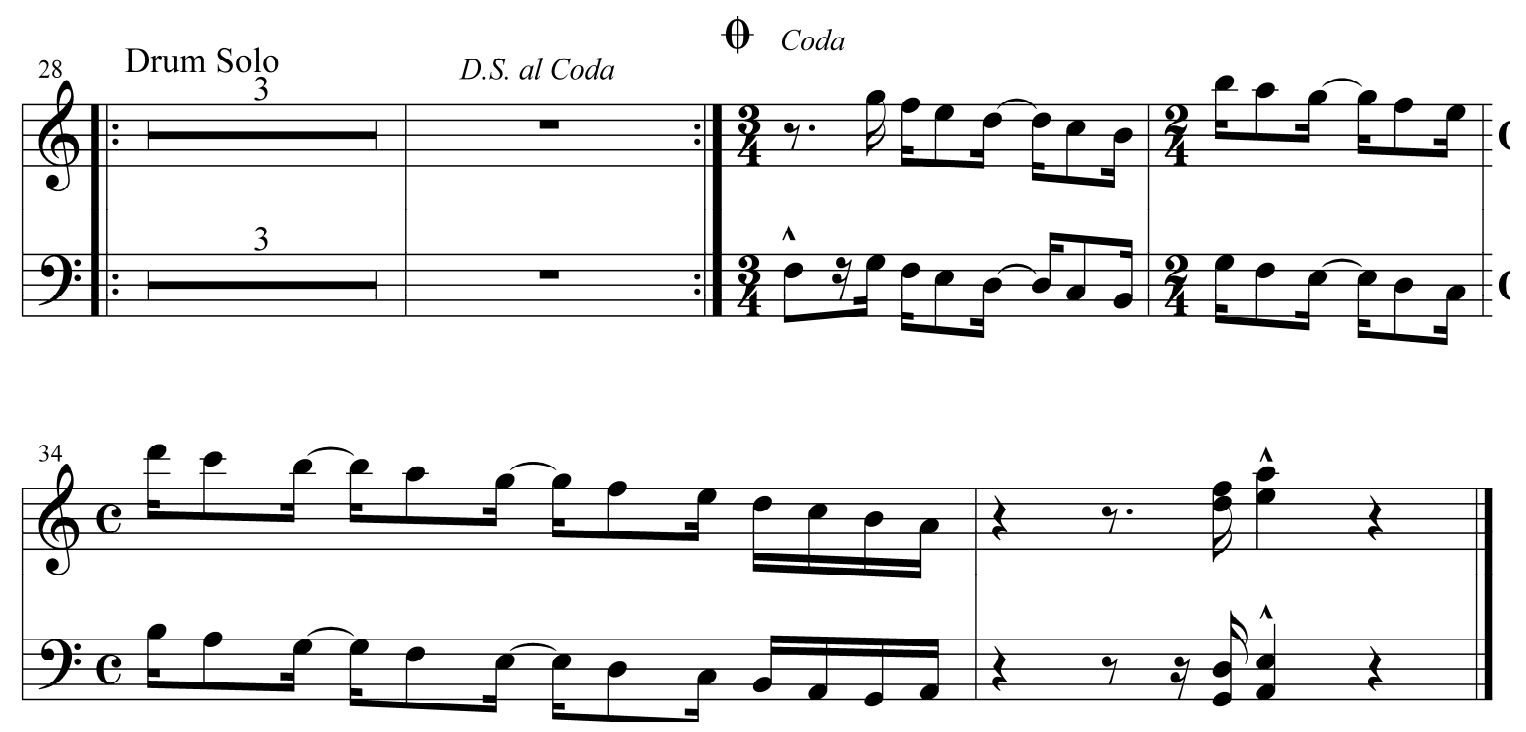

VI. NOTHING PERSONAL

The last composition of the recital "Nothing Personal” written by the brilliant jazz composer and performer Don Grolnick. I added the percussion parts. Grolnick was, in my opinion, one of the most versatile composers who uses all genres: jazz, pop, R\&B, funk, and Latin music. As mentioned earlier in this writing, my work as a player and writer has been influenced by all types of music. This tune has that combination, danceable groove, with be-bop style melody, and elaborate harmony. It has the influence of a minor blues harmony with added measures that create a twenty four-bar form.

Two additional rhythms were added. The Afro-Peruvian-rhythm called festejo, which is an old Afro Peruvian rhythm used in the family reunions and theater, the word festejo comes from festivity, even though the lyrics expresses the laments of the slaves, while the music and dance have an exuberant and festive quality. ${ }^{8}$ And the other rhythm

\footnotetext{
${ }^{8}$ For more on Festejo see, Feldman, 2009, 108-109
} 
is the straight ahead jazz feel. The tempo is fast so it fits perfect with the festejo and fast swing. The festejo rhythm is as follows for the drum set:

Example 10 Nothing Personal Drum Set Pattern

Drum Set

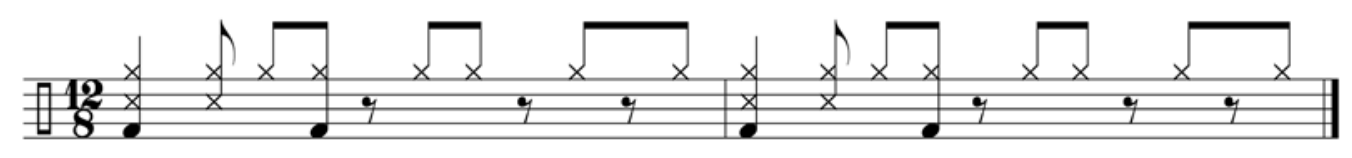

For the Cajon:

Example 11 Nothing Personal Cajon Pattern

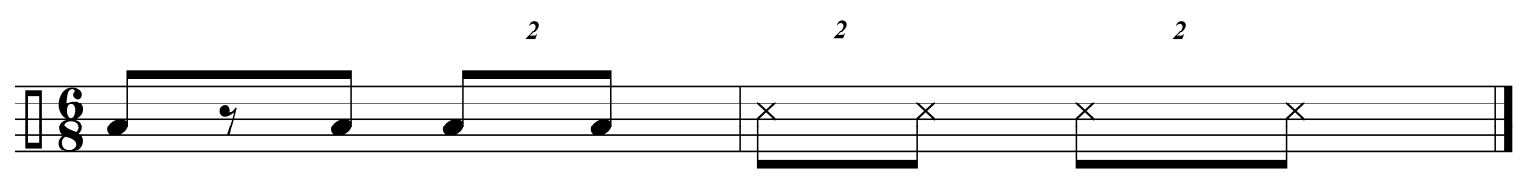

“Nothing Personal” is a twenty four measure head, is as follows:

(16 mm.) of festejo rhythm, (4 mm.) of straight ahead swing, and back to (4 mm.) of festejo. The introduction starts with an authentic bass and guitar festejo line. This arpeggiatted line is what establishes the groove along with the drum set, congas, cajon, and quijada de Burro, which is a donkey's jaw that is played by scraping or hitting it with a thin stick. This instrument has been used since the XVIII century. ${ }^{9}$ The rhythm section maintains the festejo groove with intensity but not loud until the song reaches its climax. The authentic bass and guitar festejo line is as follows:

\footnotetext{
${ }^{9}$ See Feldman 2009, 39
} 


\section{Example 12 Nothing Personal Guitar \& Bass Pattern}

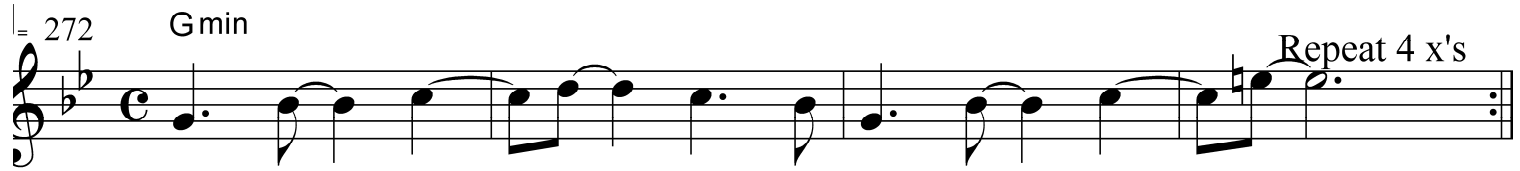

The melody has an exciting bebop line that uses arpeggios, scales, and chromatic movements. It leaves spaces for the drummer to fill in and interact with the melody. In addition, the drummer prepares the ensemble accents. The harmonic progression is a $G$ minor blues with added measures. Instead of a regular twelve-bar blues the chords are doubled. The basic blues progression for $\mathrm{G}$ minor is: $\mathrm{G}$ minor for (4 mm.), C minor7 for (2 mm.), back to G minor for (2 mm.), D7 for (1 mm.), C minor7 for (1 mm.), and it finishes with the $\mathrm{G}$ minor for (2 mm.). Doubling the length of measures per progression converts this composition in a twenty-bar blues. The progression is as follows: $\mathrm{G}$ minor for ( $8 \mathrm{~mm}$.), C minor7 for (4 mm.), and back to $\mathrm{G}$ minor for (4 mm.). Then instead of going to the iv-V7-i progression, it goes to the bVI7-V7-i.

The melody is played twice before solos. The solos follow the song form and each soloist plays four choruses. The first two times there is a switch of rhythms between festejo and swing, the third and fourth time the rhythm section stays in straight ahead swing feel all the way through. Finally, there are two choruses' trade between the percussion and melodic instruments maintaining the festejo rhythm. Immediately after goes back to Da Capo, for an open drums and percussion solos until the cue back to the melody. The melody is repeated twice, then the coda. And the coda is a twenty-measure straight ahead swing that builds up to the last beat of the last measure. 


\section{CONCLUSION}

The recital is based on the use of an assortment of methods and musical elements to create this particular fusion of American Jazz, World Music, and Latin American folkloric rhythms. One must carefully understand the rudiments of each particular style and produce a balance that will define the sound desired.

Simpkins, in his book mentions about Coltrane, that "His explorations and synthesis of different music of the world continued in what he saw as a never-ending endeavor." ${ }^{10}$ Music continues and the more a musician grows, the more elements will contribute to its creativity. It is obvious that musical thoughts unites the emotional with spiritual, but by co-writing, performing, and analyzing these five creative arrangements, one can examine the balance of elements, identify where they come from, and witness the end result.

\footnotetext{
${ }^{10}$ Simpkins, 1975, 193
} 


\section{LIST OF REFERENCES}

Feldman, H. C. (2006). Black rhythms of Peru : reviving African musical heritage in the Black Pacific. Middletown, Conn., Wesleyan University Press.

McGowan, C. and R. Pessanha (2009). The Brazilian Sound. Philadelphia

Pensylvannia, Temple University Press.

Moura, D. (2007). Grooves do Brazil. Portland, Oregon, Tapspace Publication.

Nicholson, S. (1998). Jazz Rock: A History. New York, Schimer Books.

Roy, M. (2002). Cuban Music. Princeton, New Jersey, Marcus Weiner Publishers.

Simpkins, C. O. (1975). Coltrane a Biography. Baltimore, MD. Black Classic Press

Uribe, E. (1996). The Essence of Afro-Cuban Percussion and Drum Set. Miami, Warner Bros. Publications. 


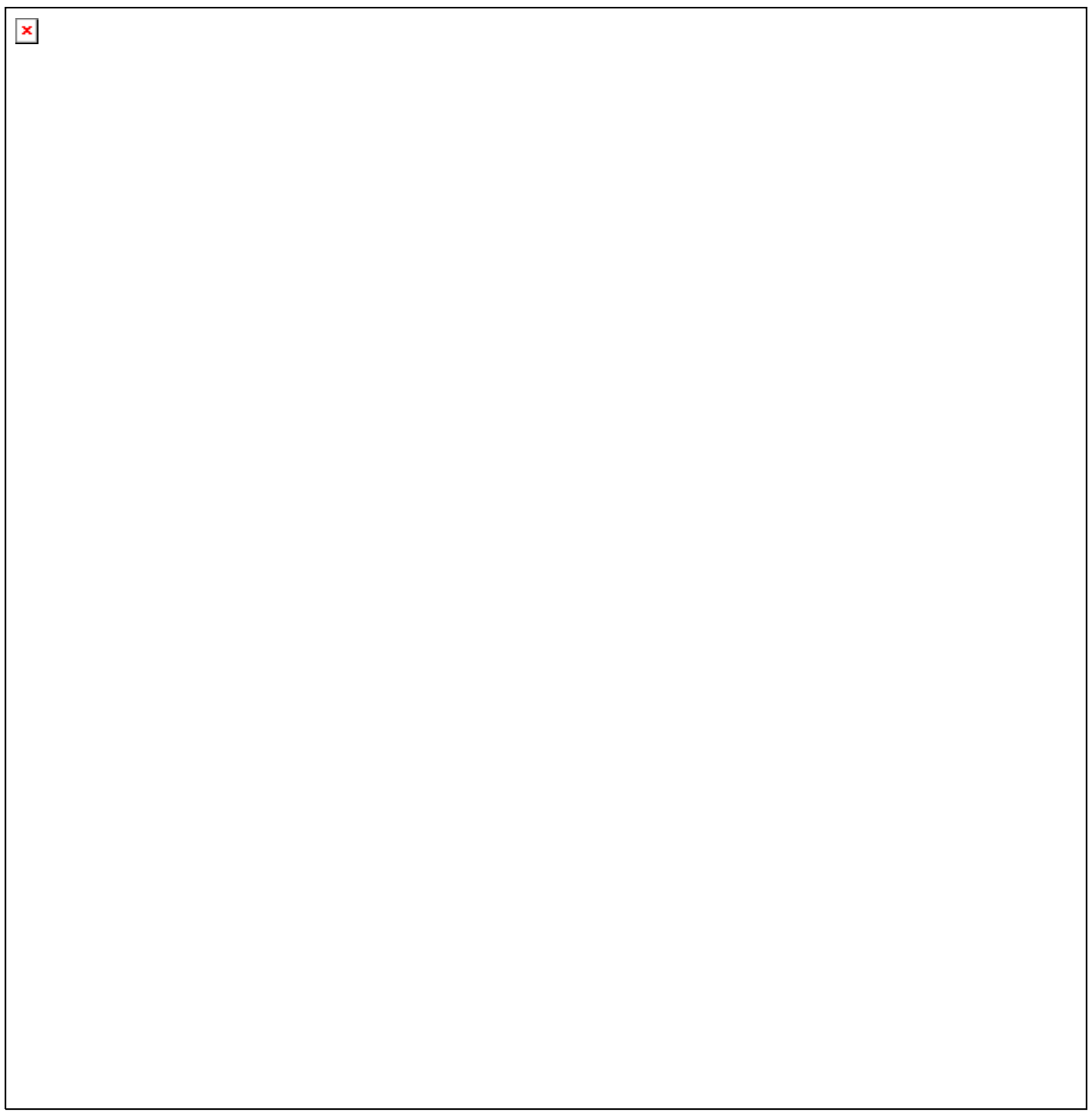


$\mathrm{x}$ 
$x$ 
$\mathrm{x}$ 


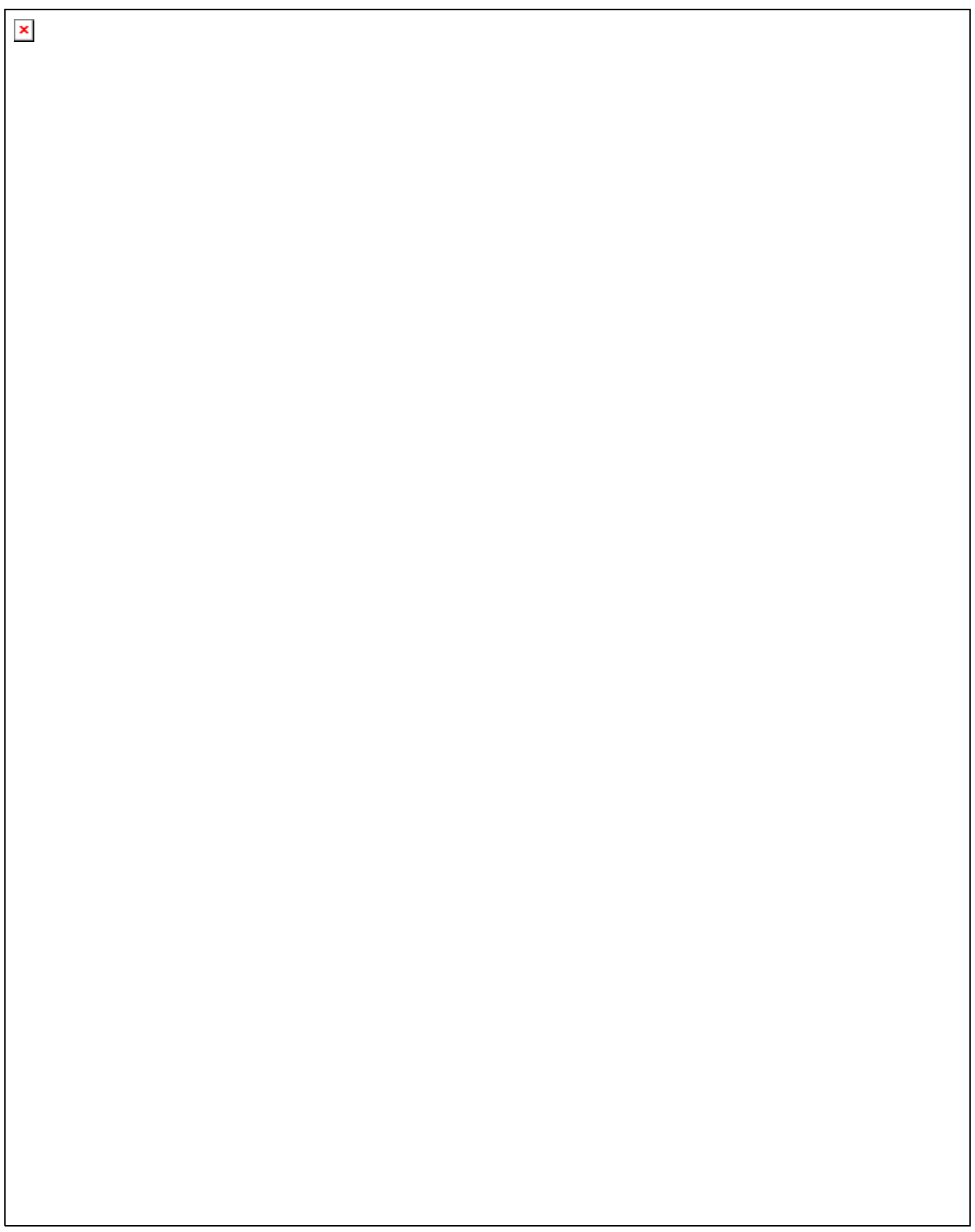




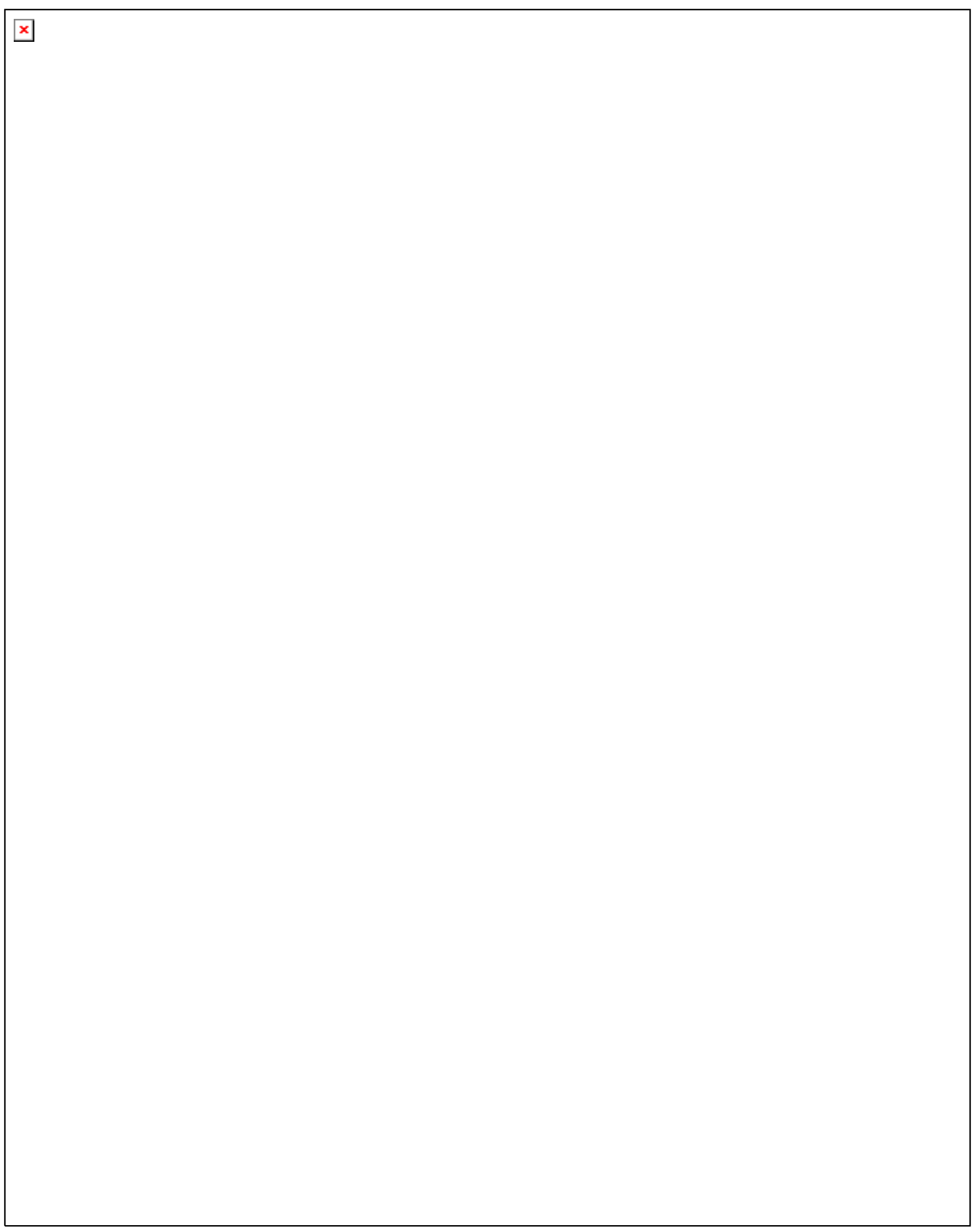


$x$ 


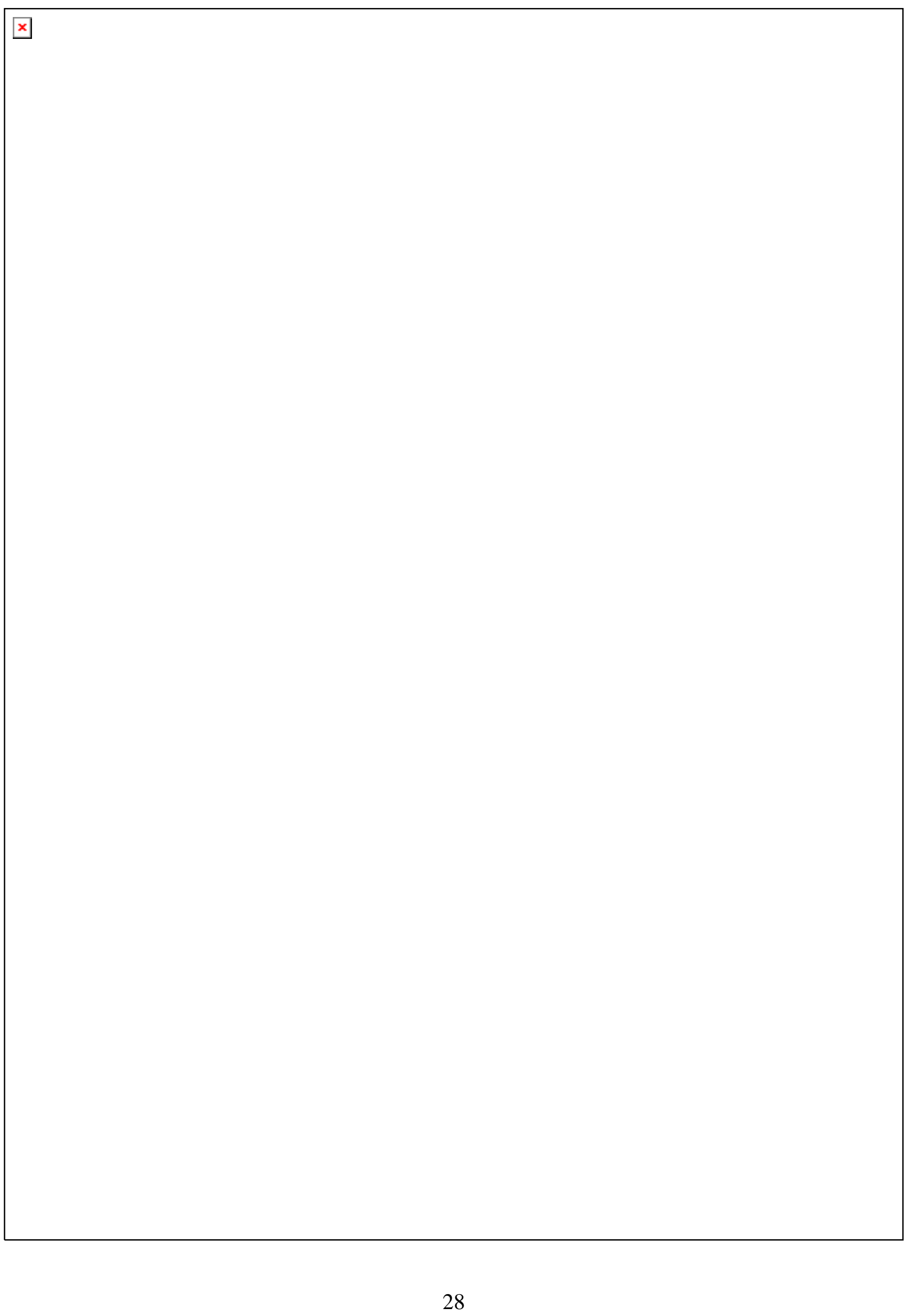


$\mathrm{x}$ 
$\mathrm{x}$ 


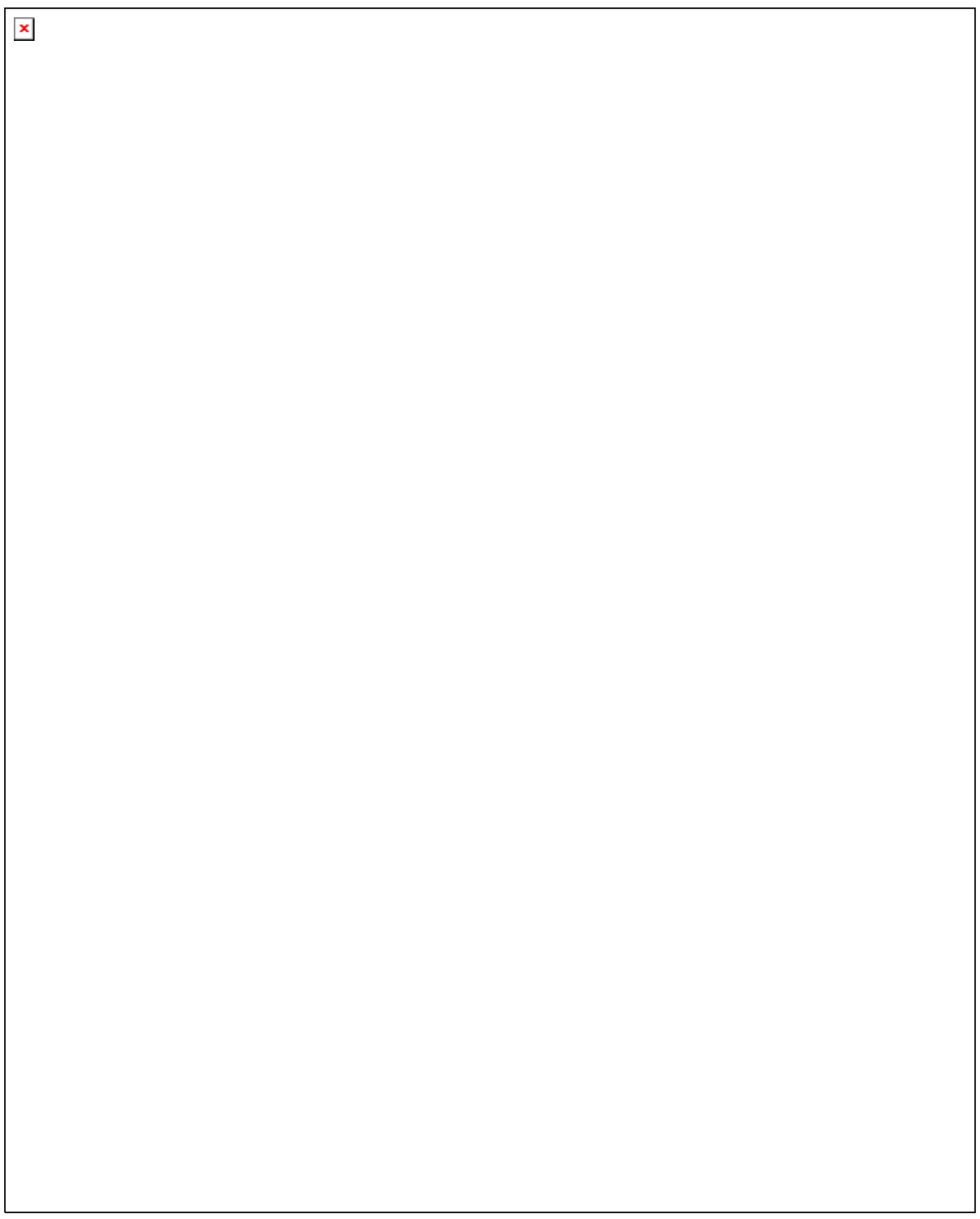




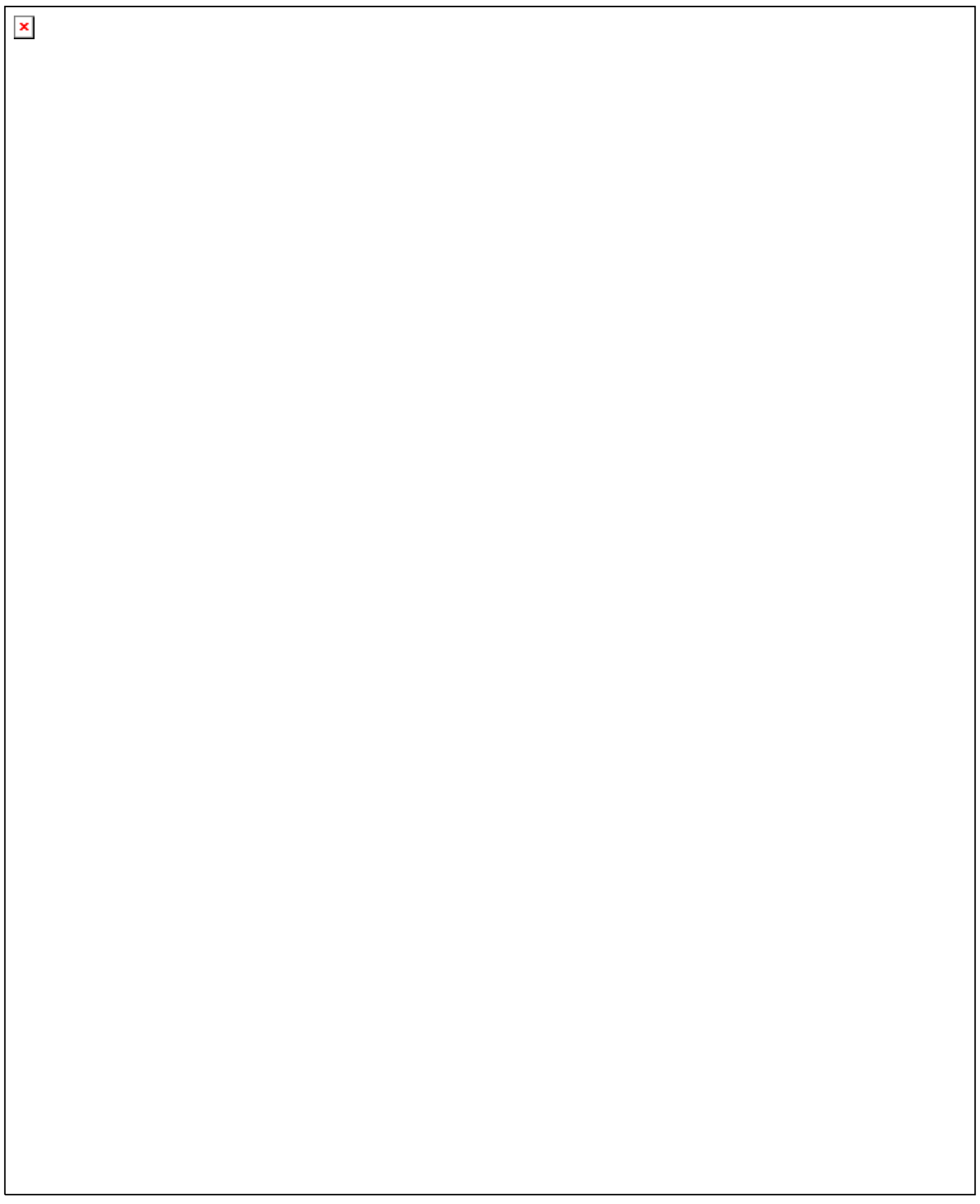




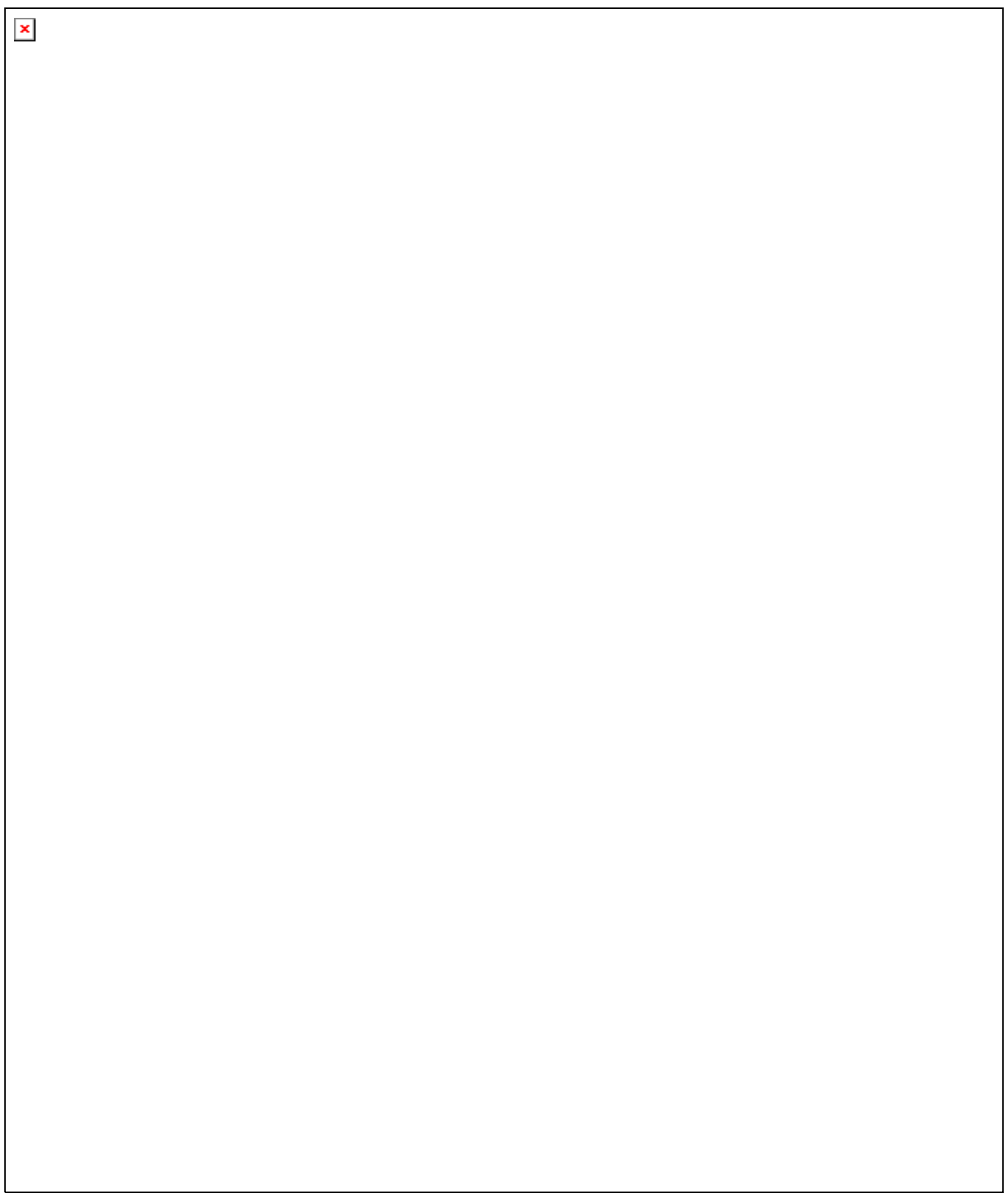




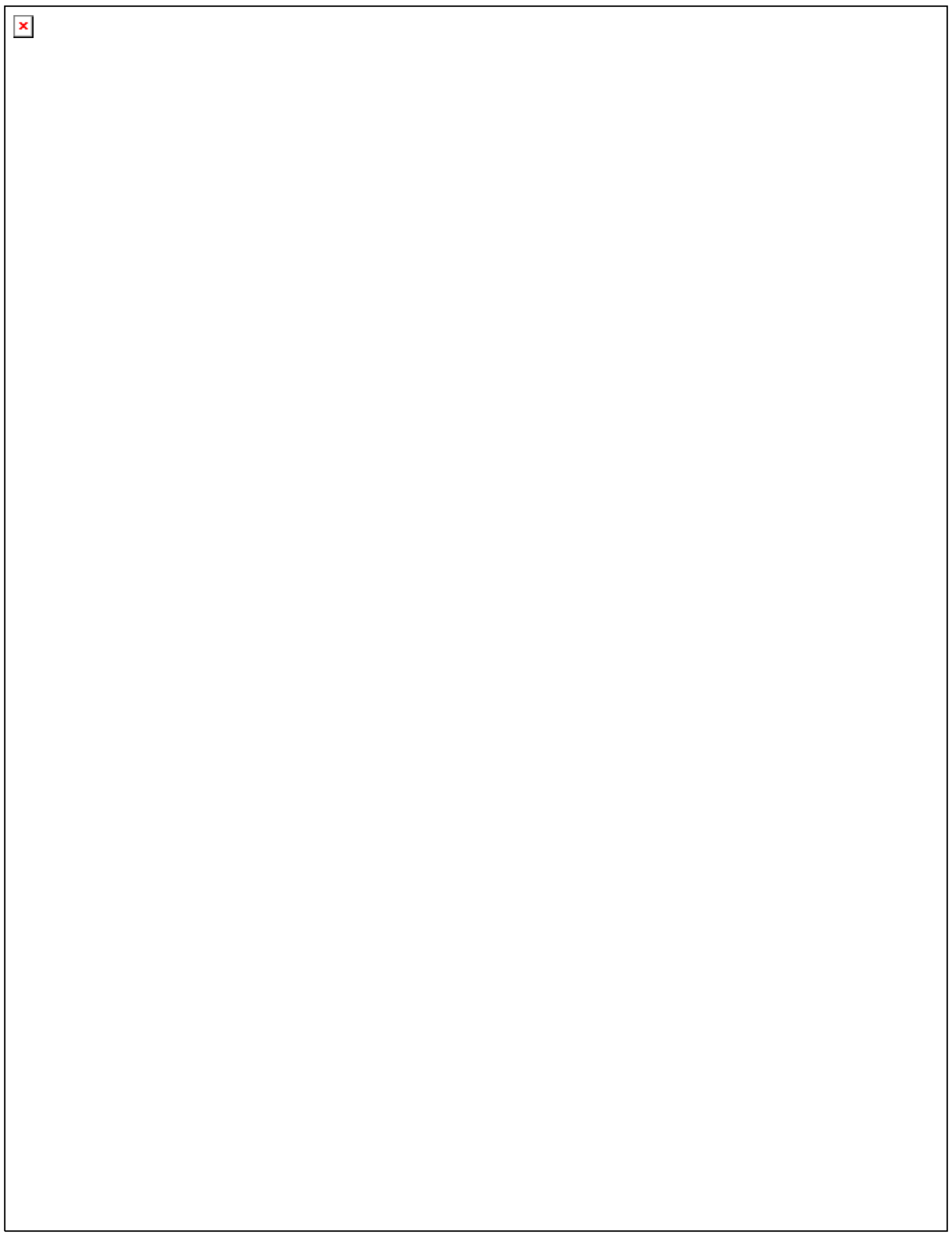




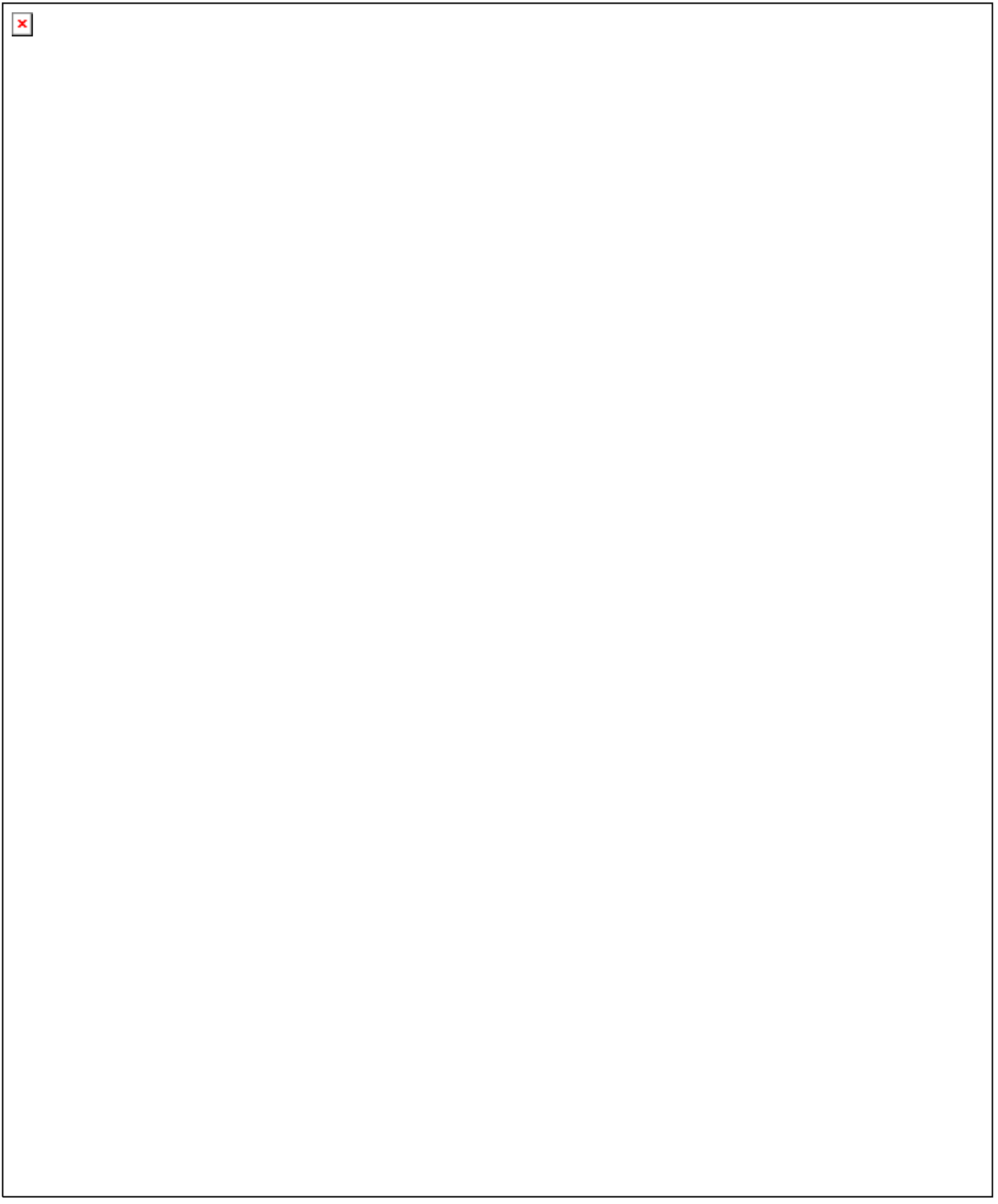


$\mathrm{x}$ 


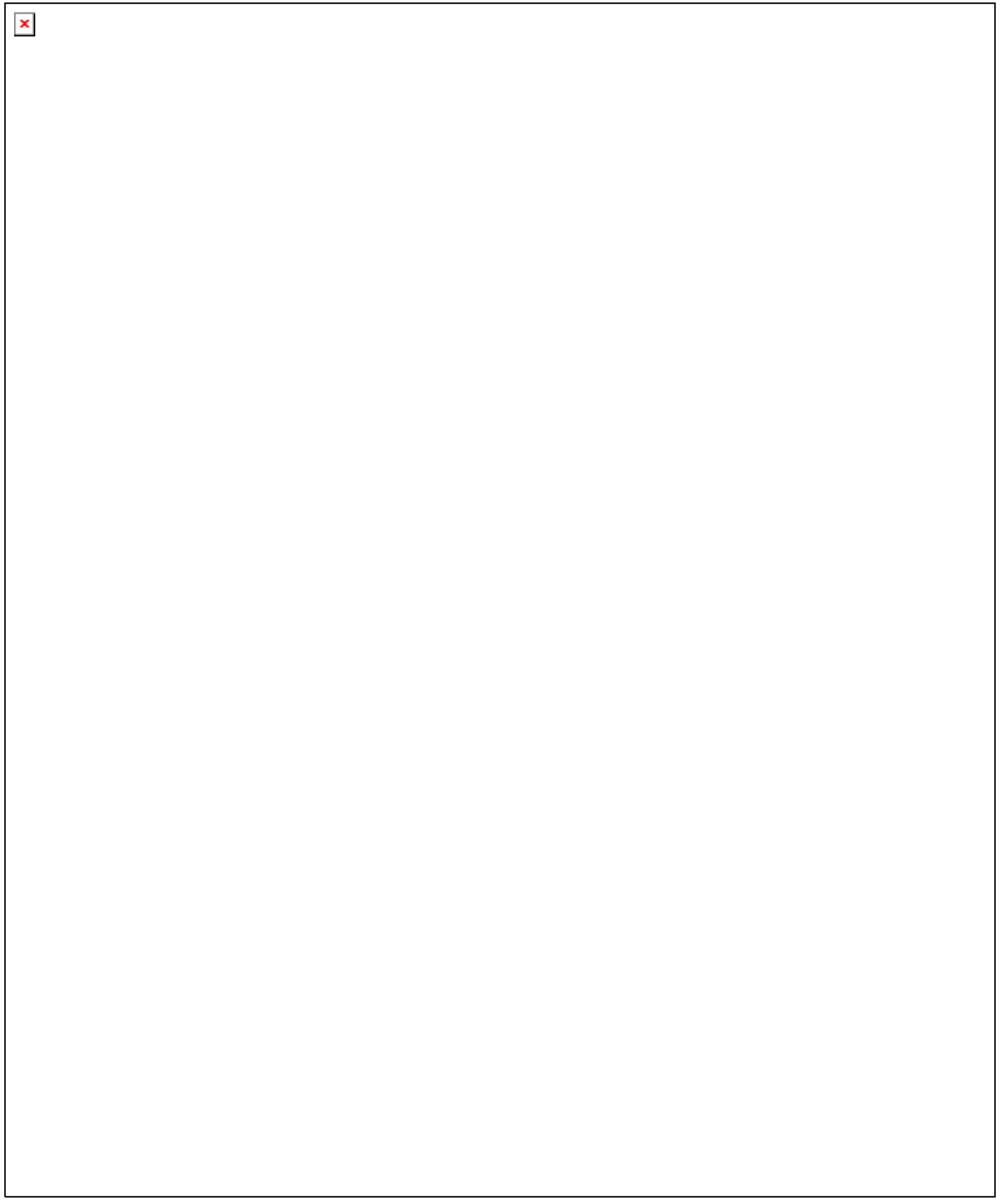


$x$ 
$x$ 
$\mathrm{x}$ 


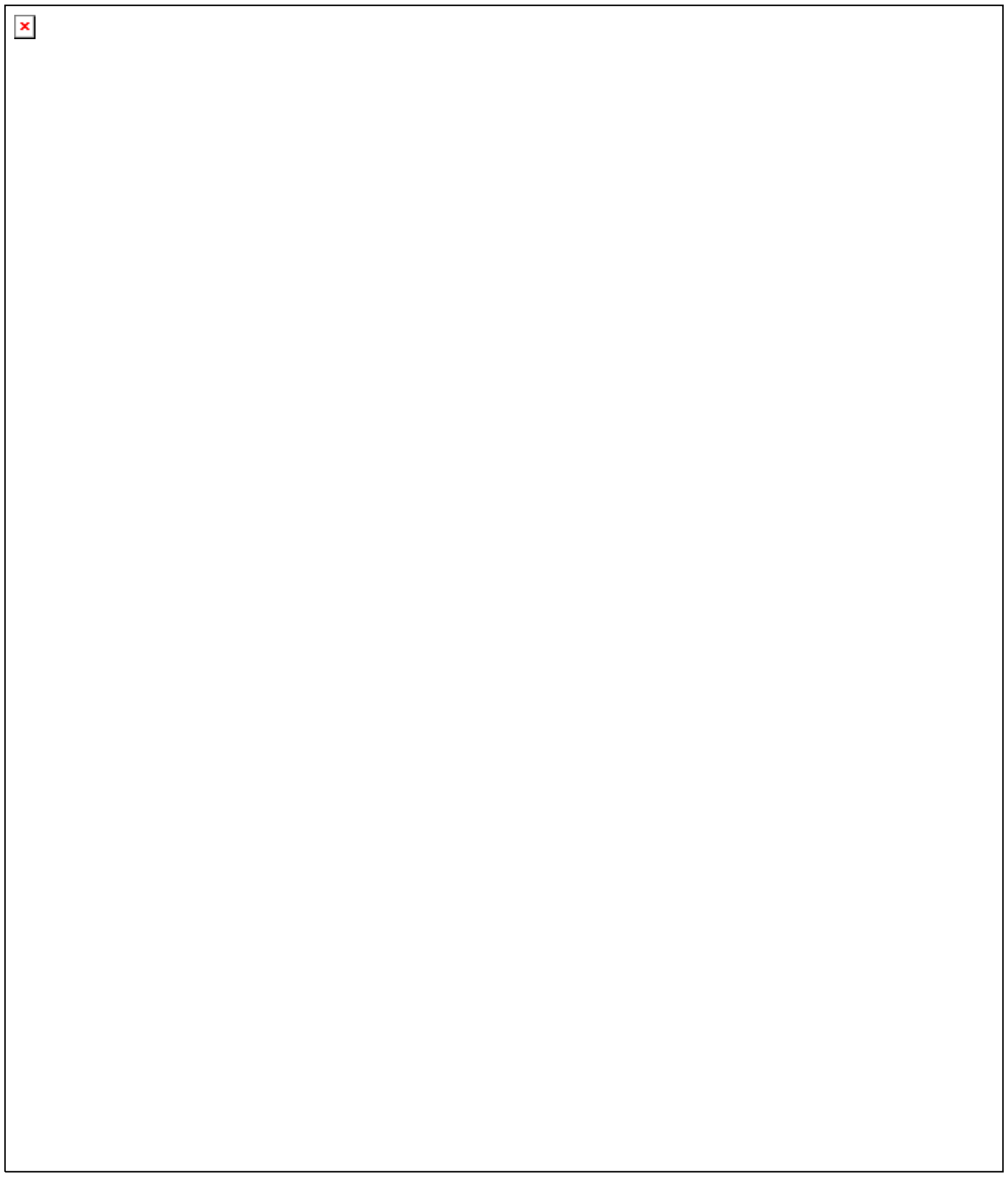




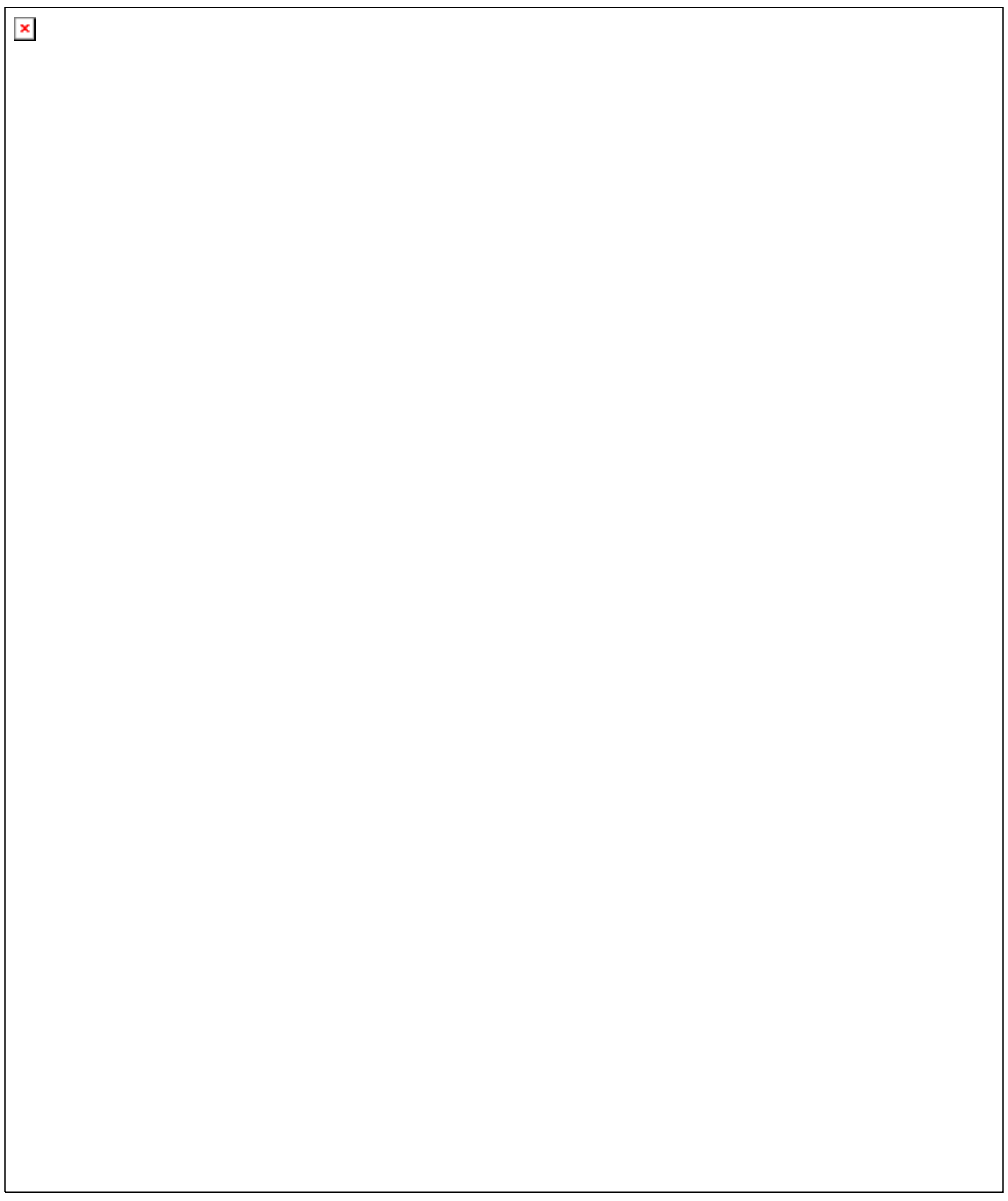


$x$ 


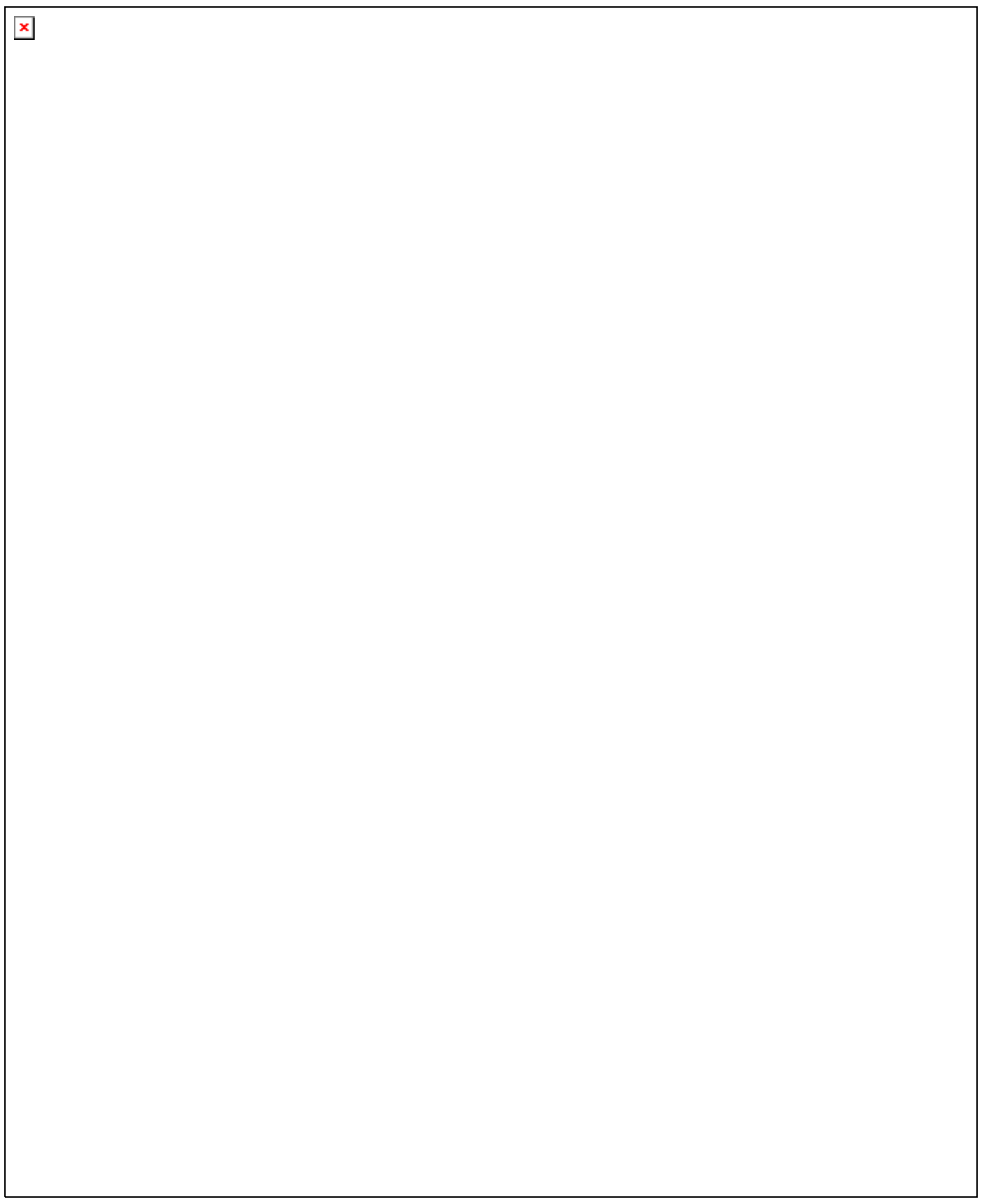




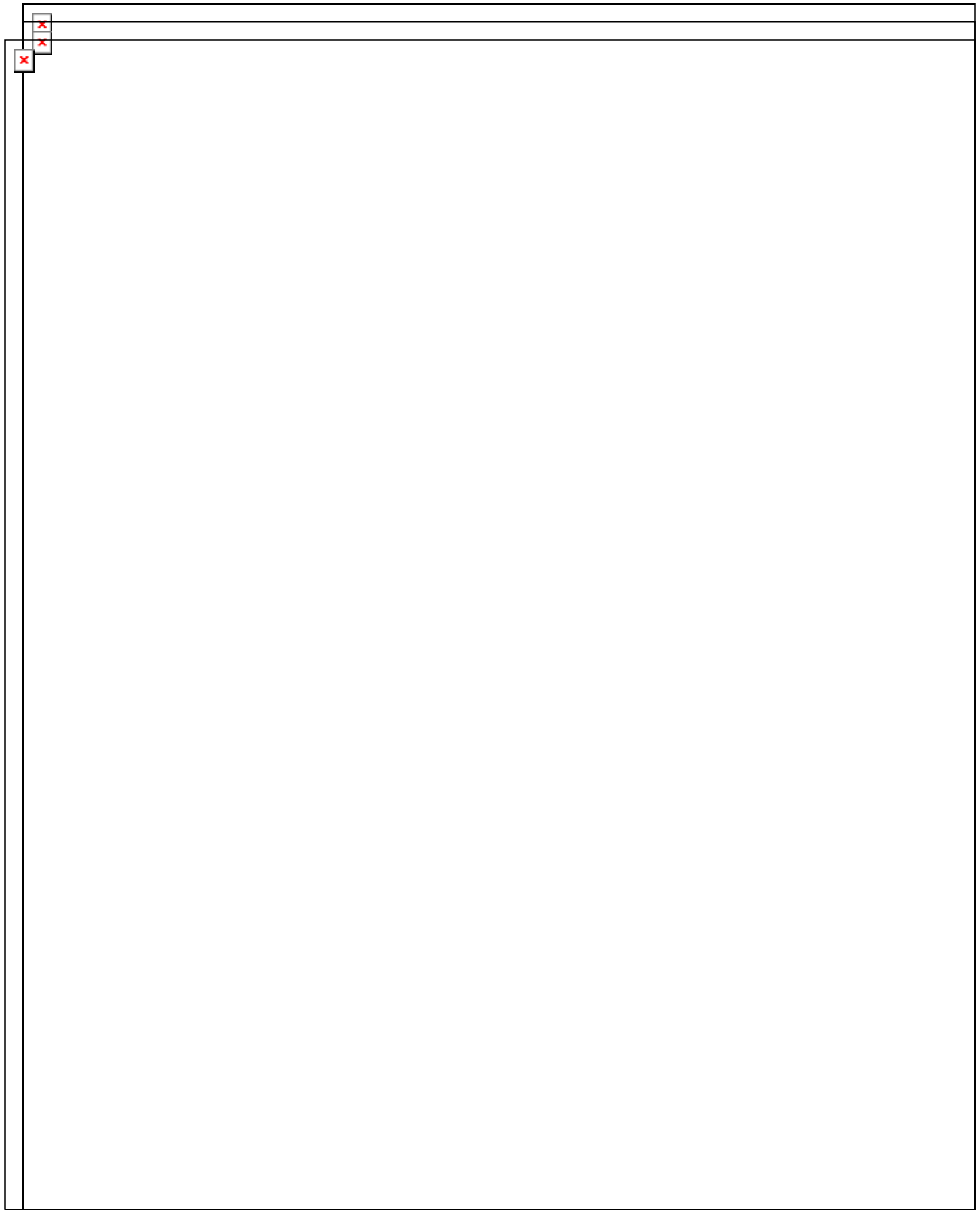


$x$ 
$x$ 


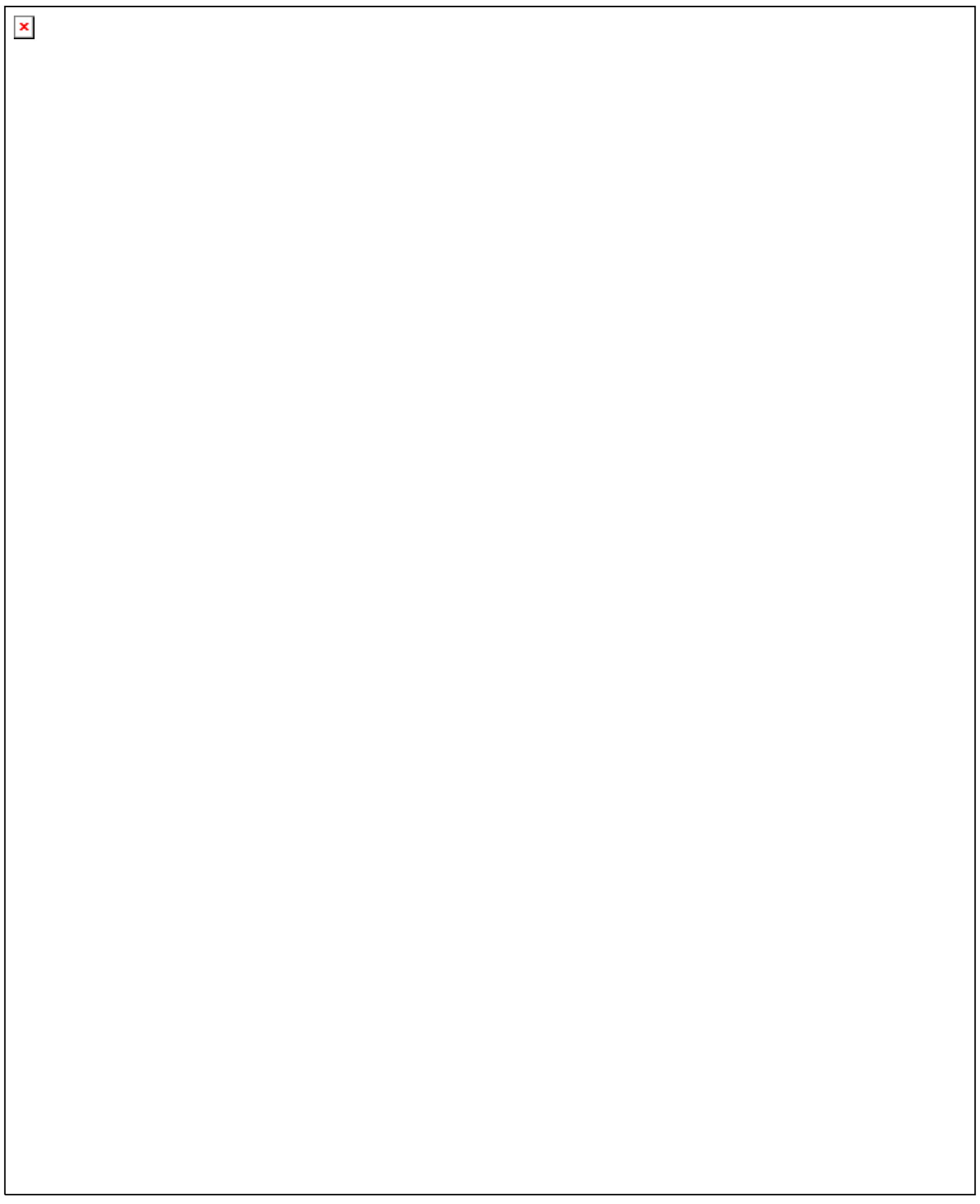




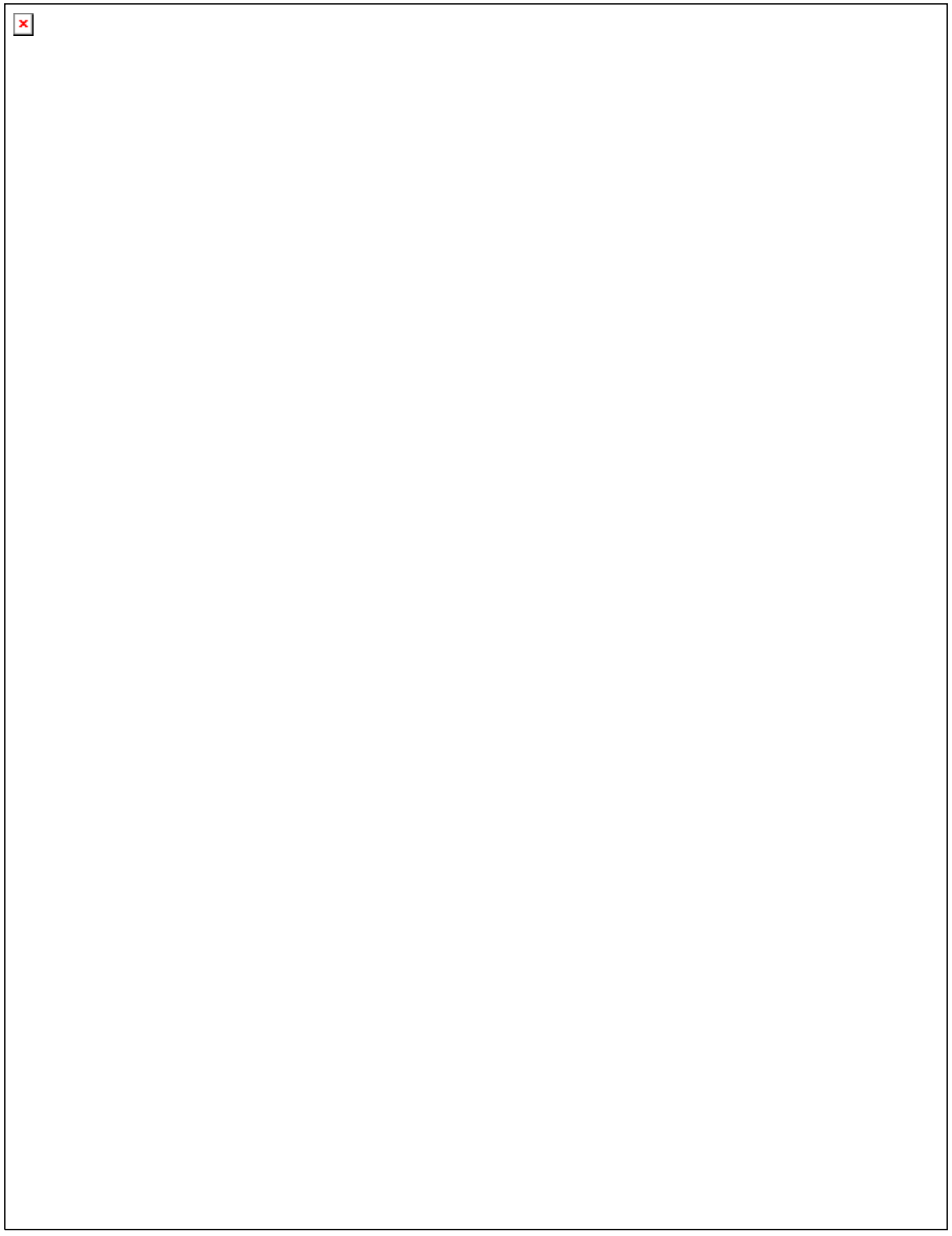




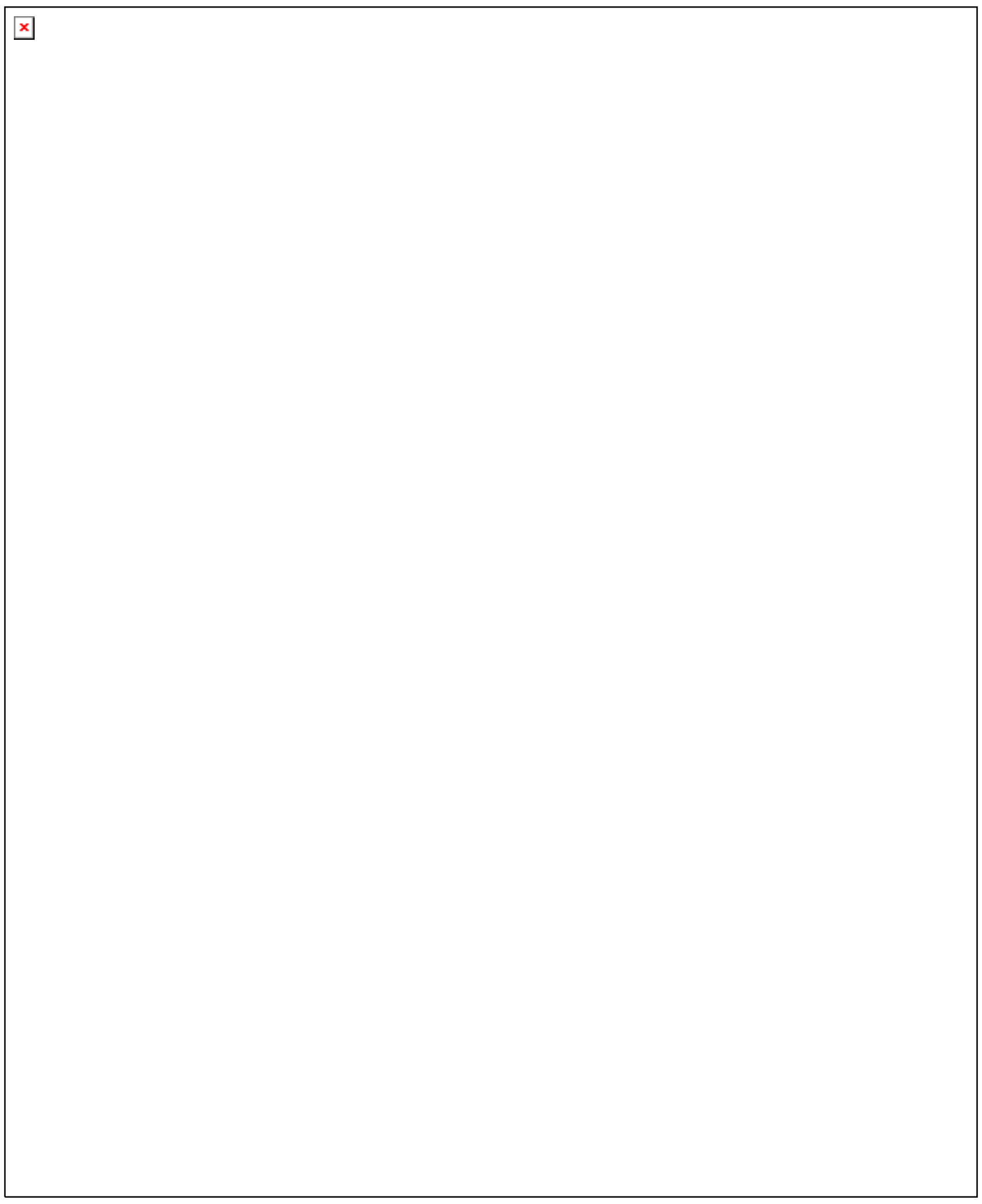


$x$ 


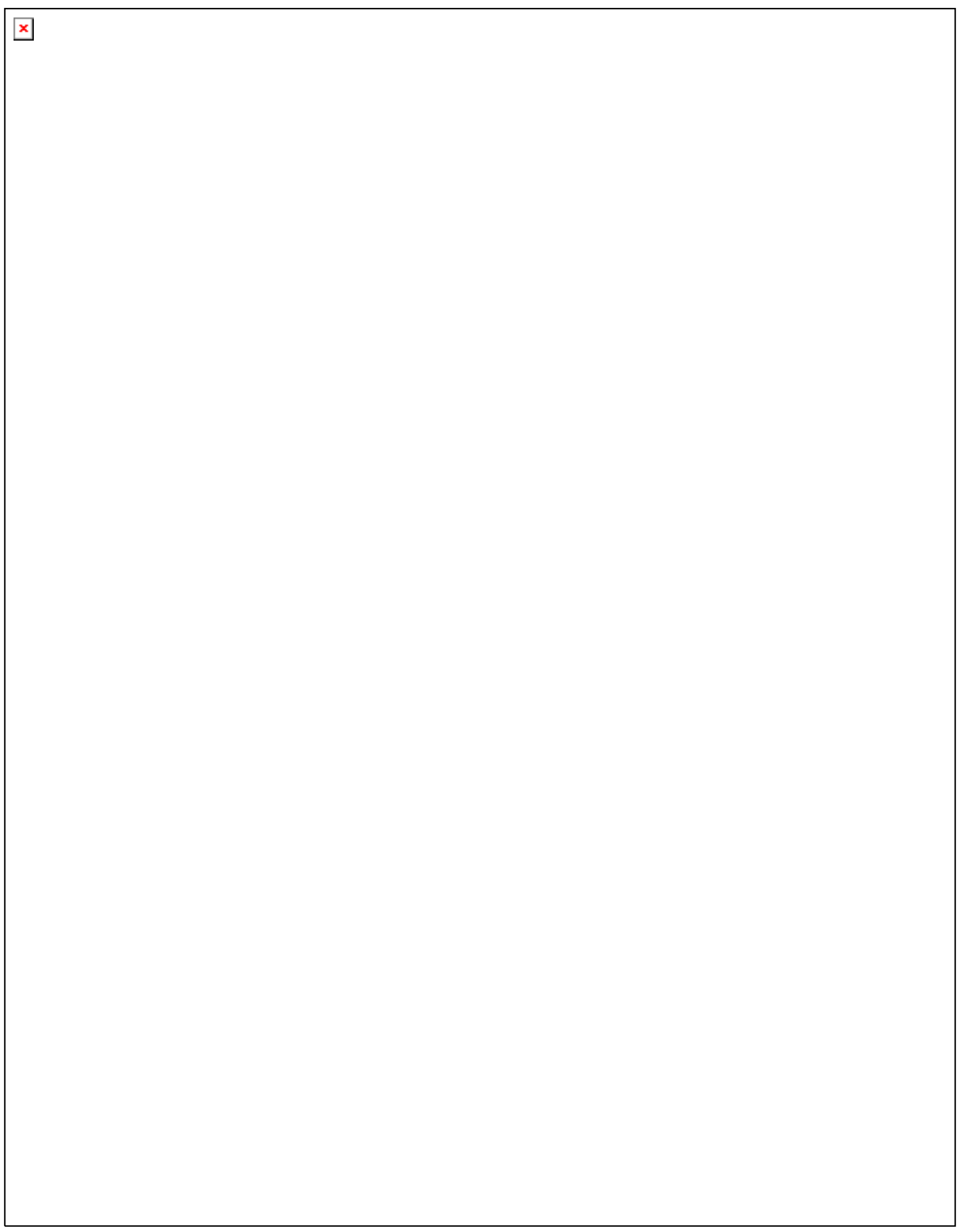




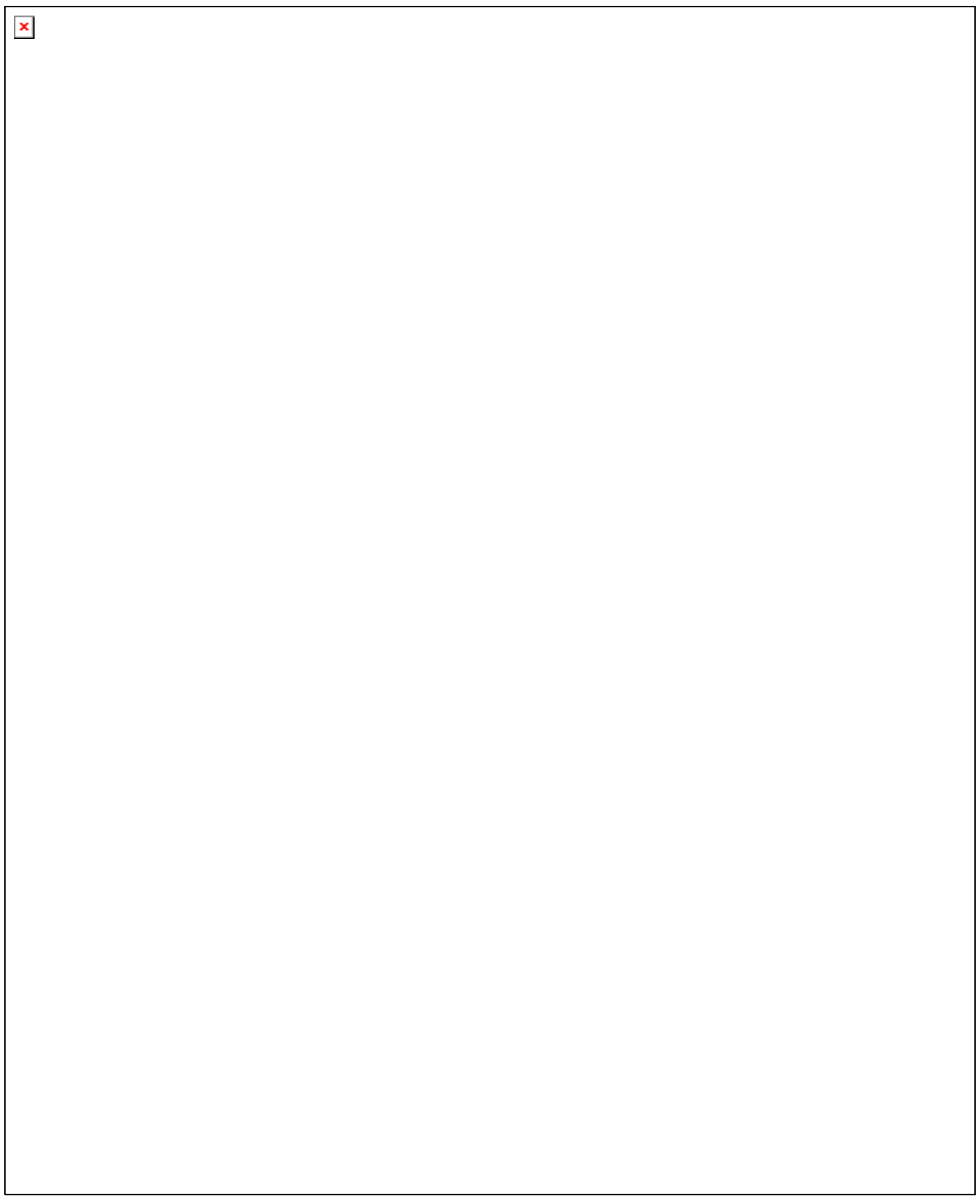




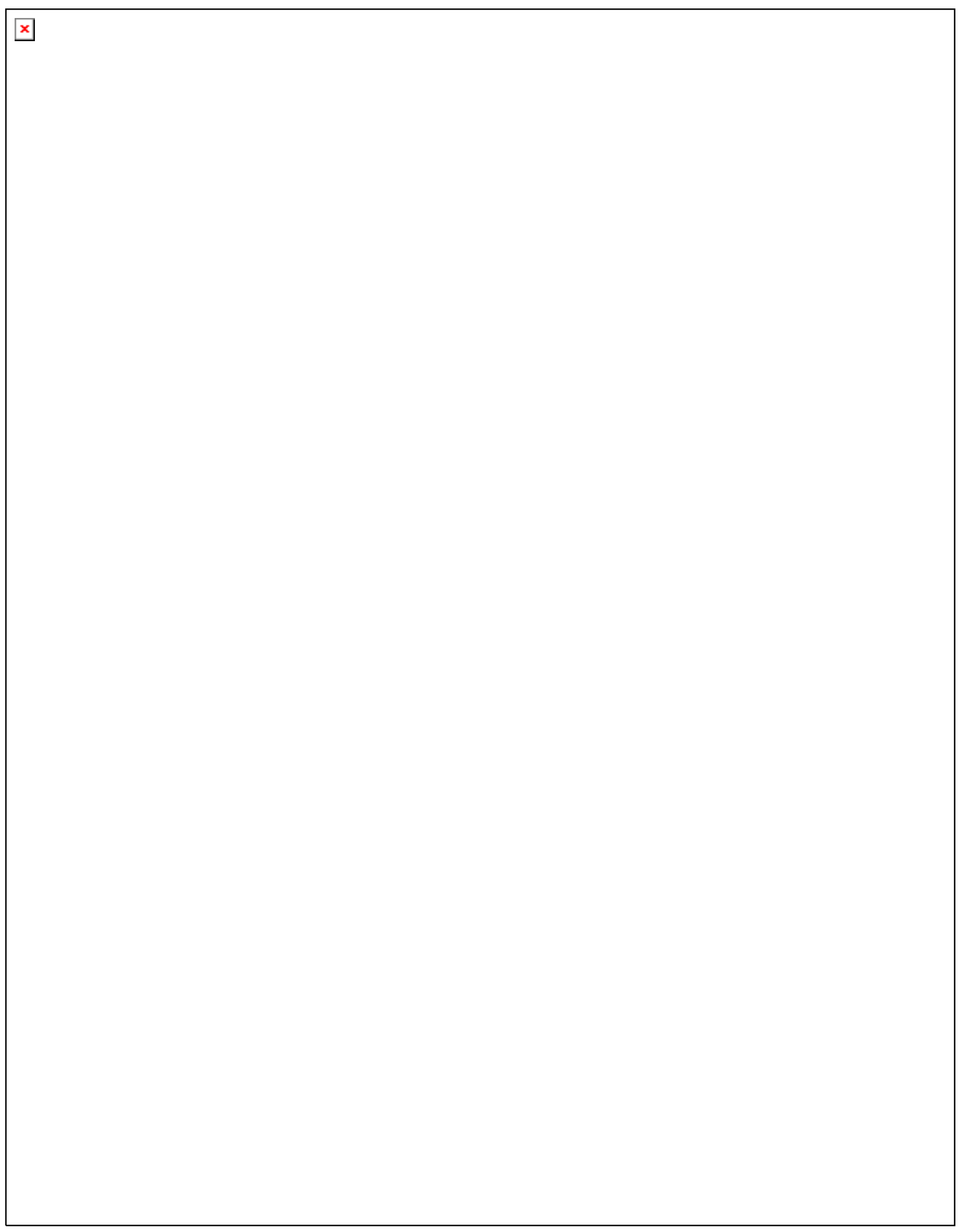




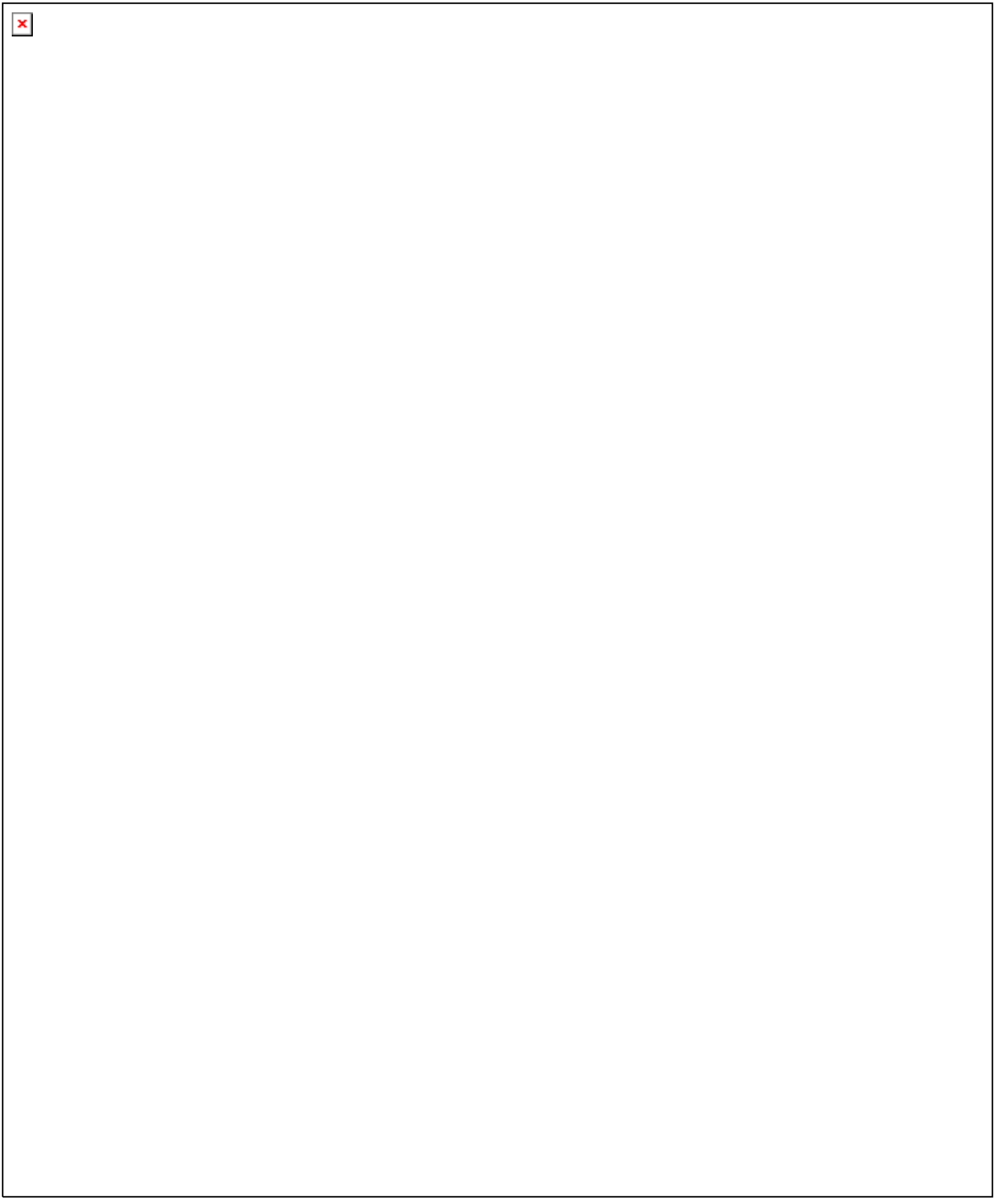


DWARF STEPS

SCORE IN C

(CONCERT PITCH) tribute to joHn coltrane

fast LatiN

A

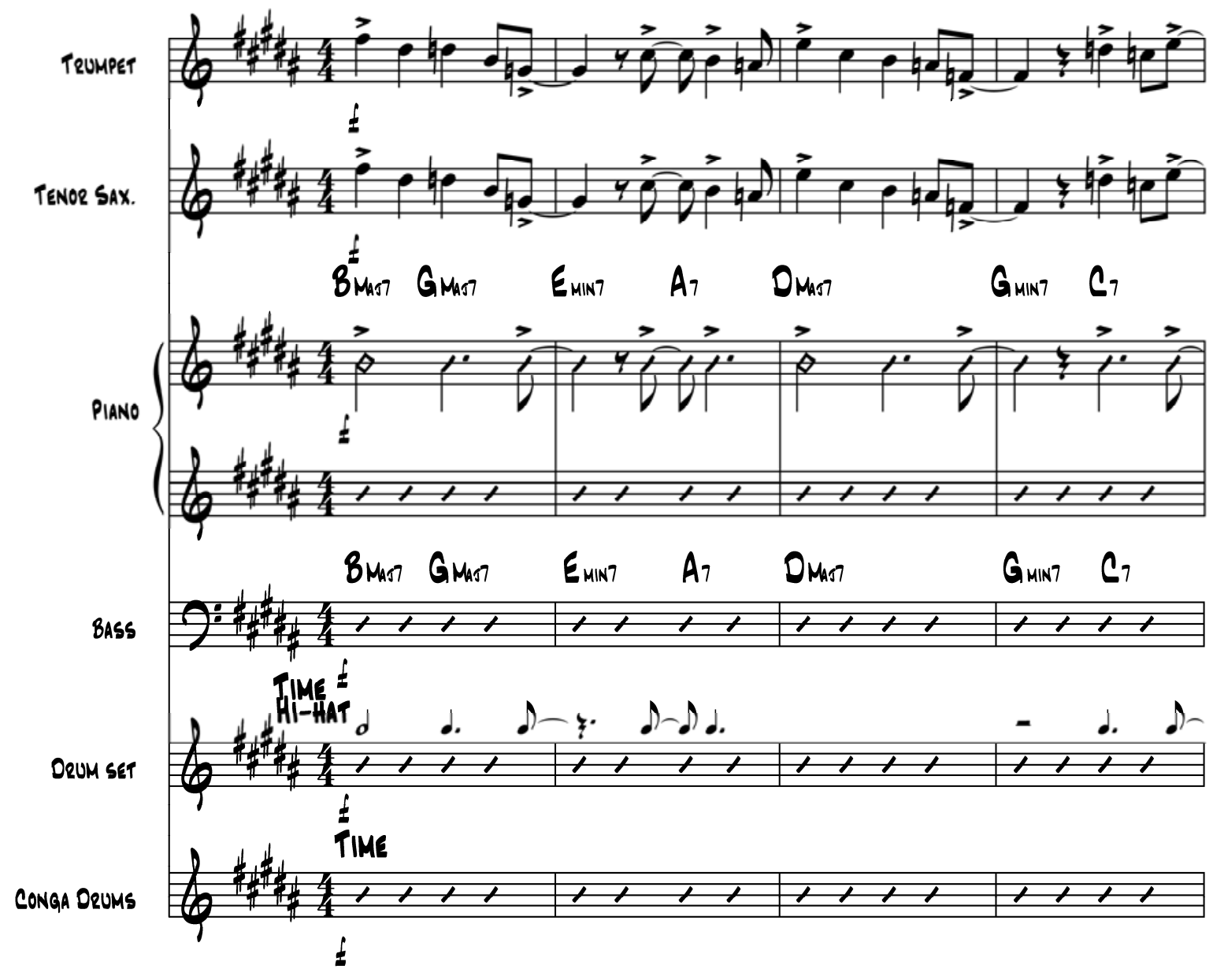

C 2010 by CPH

56 

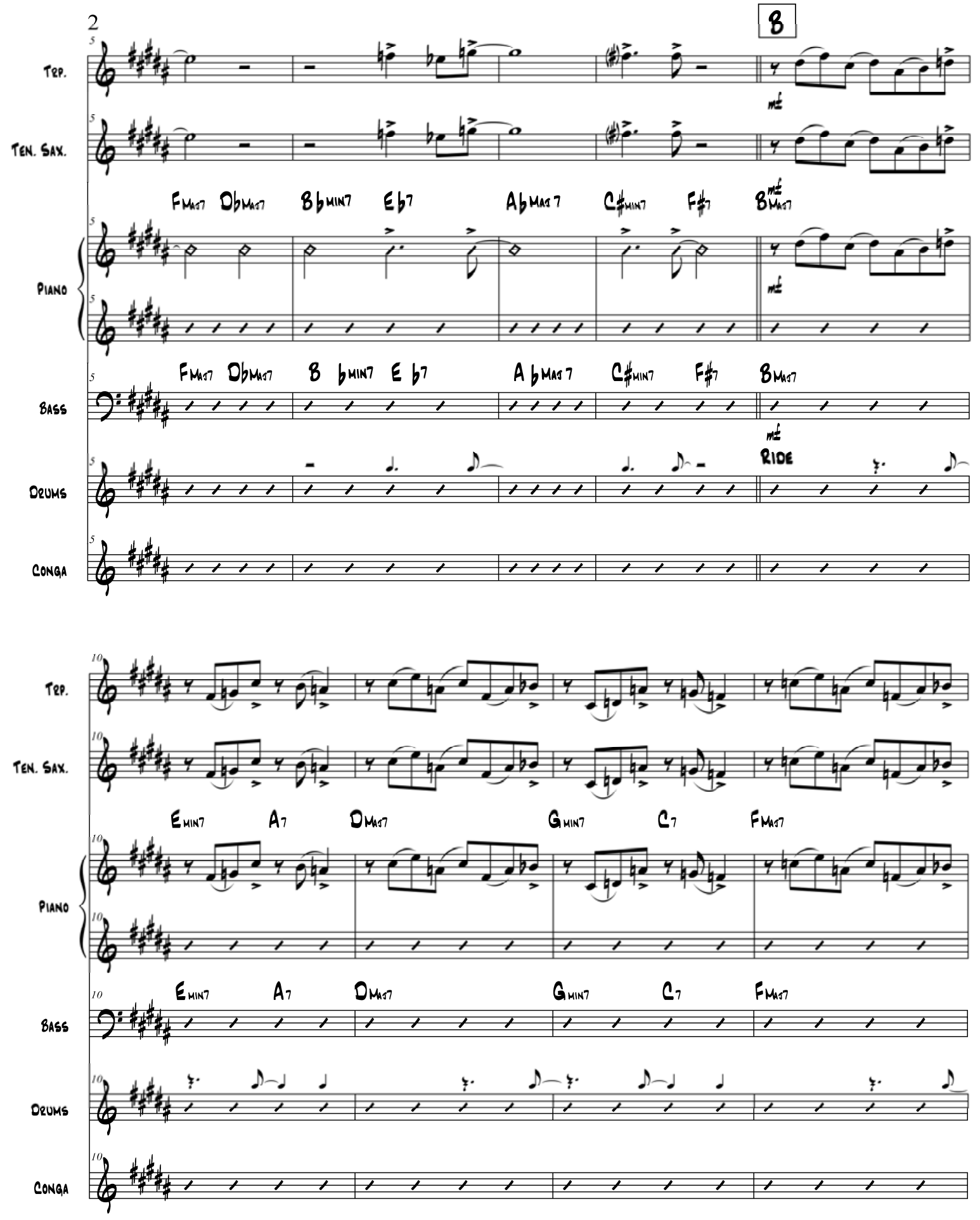

57 


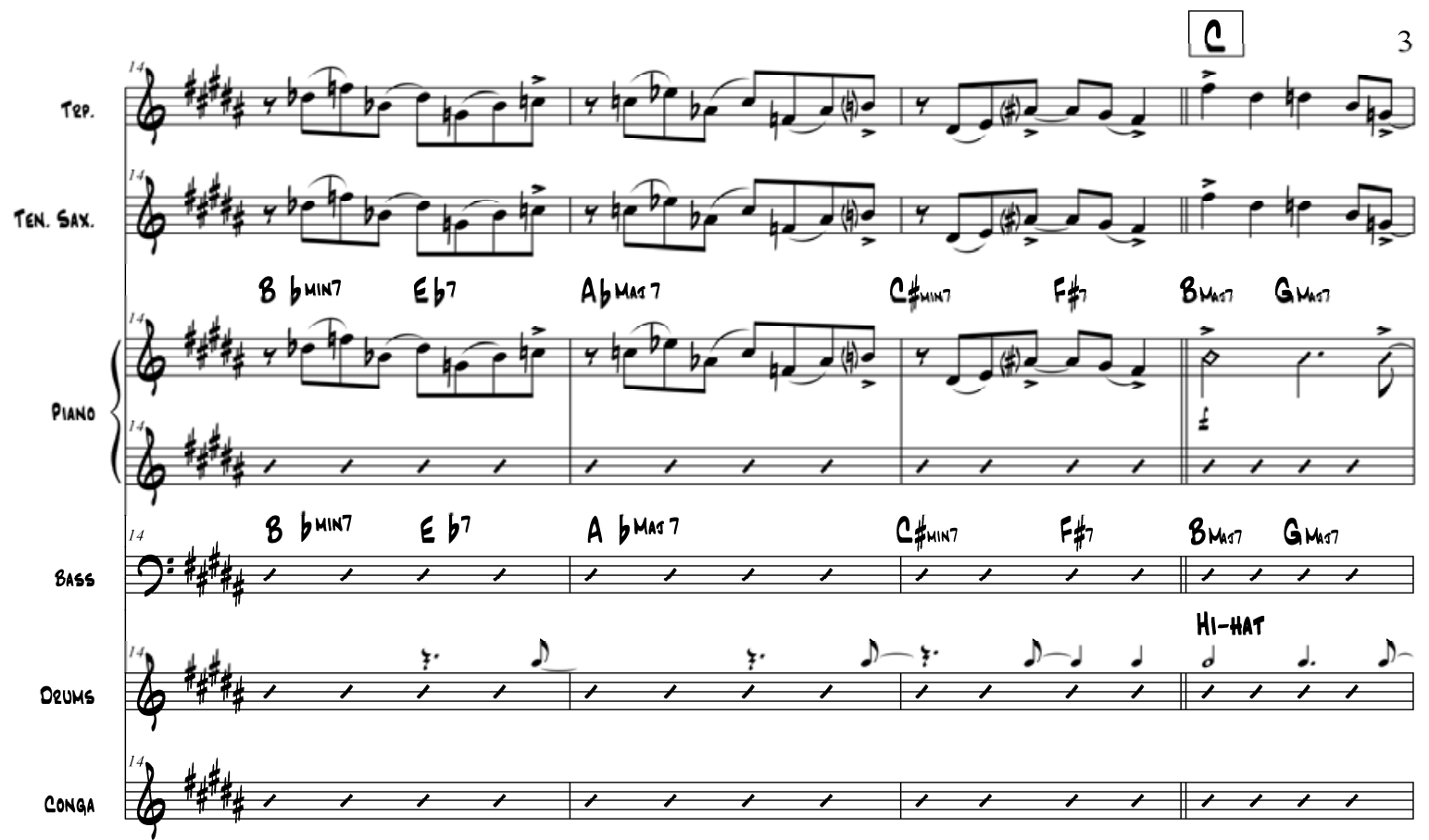

$\theta$
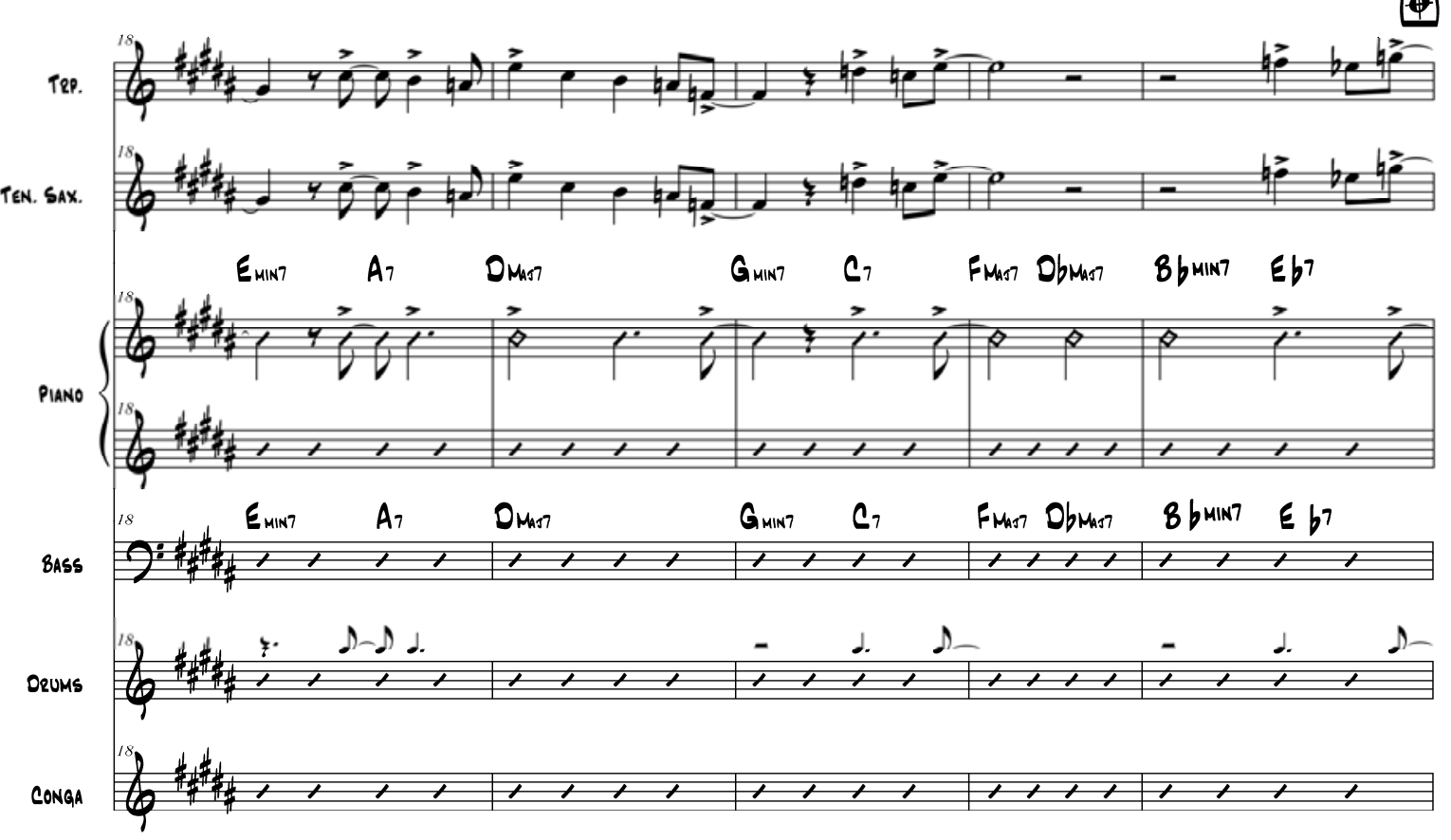

58 


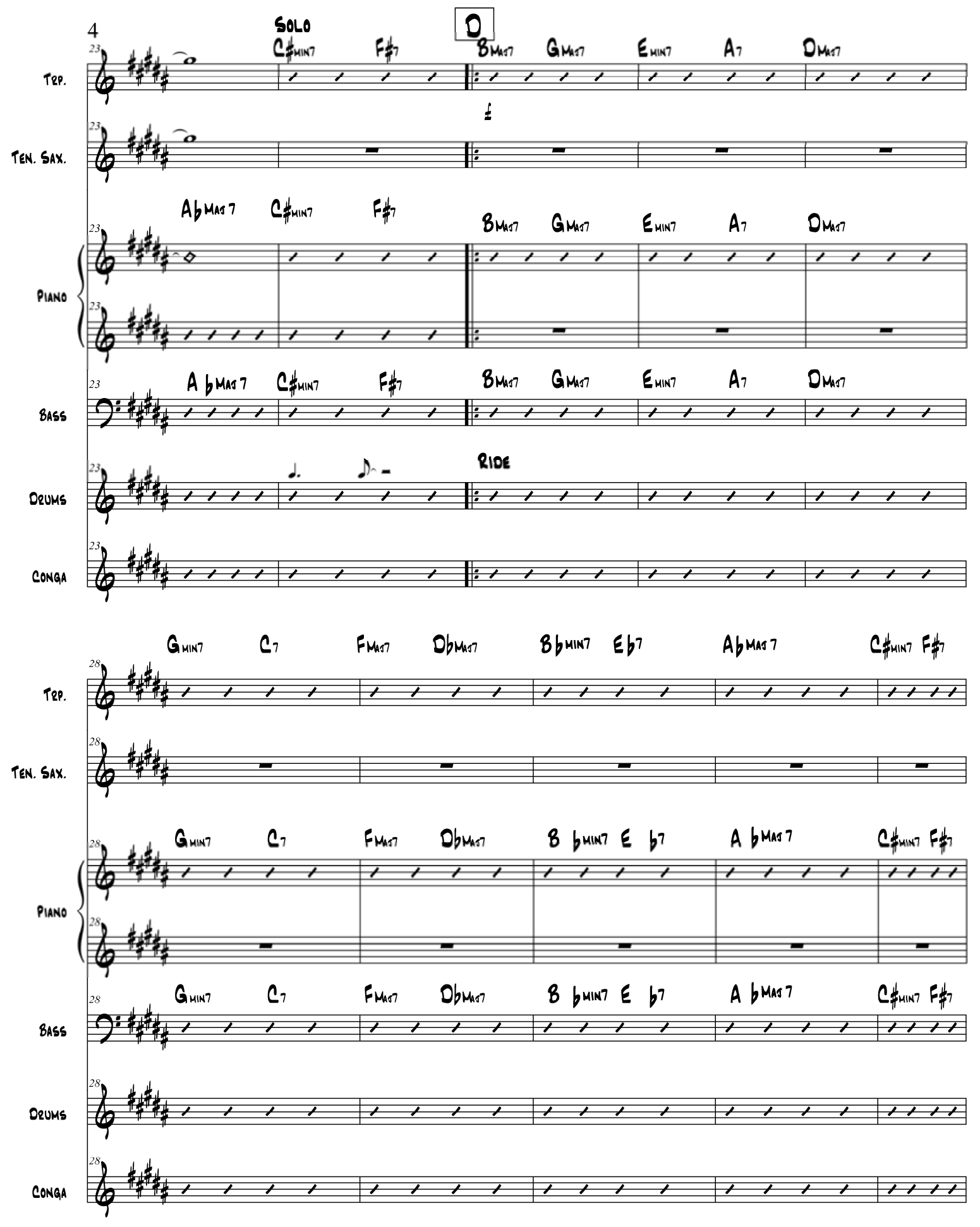

59 

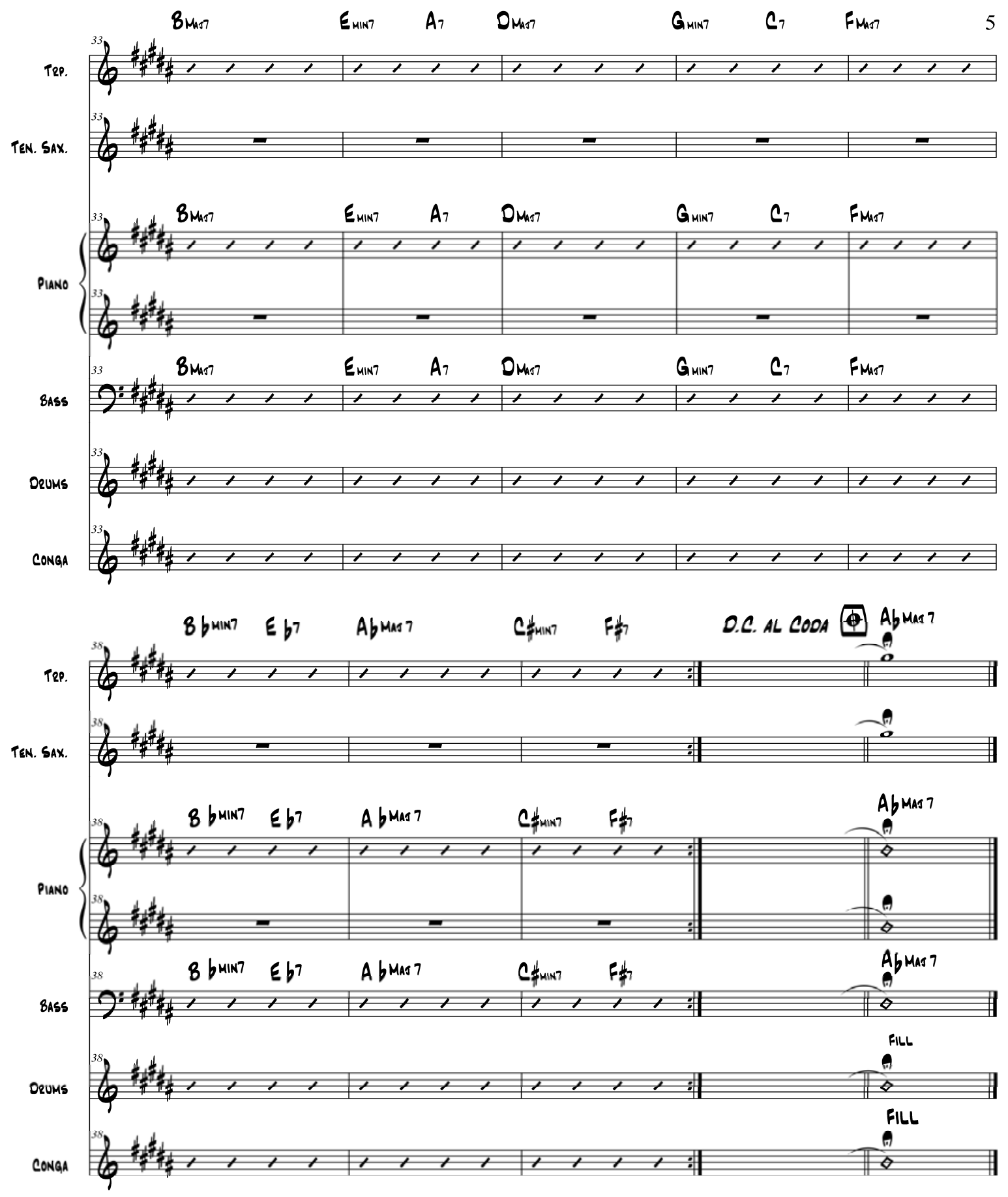

60 


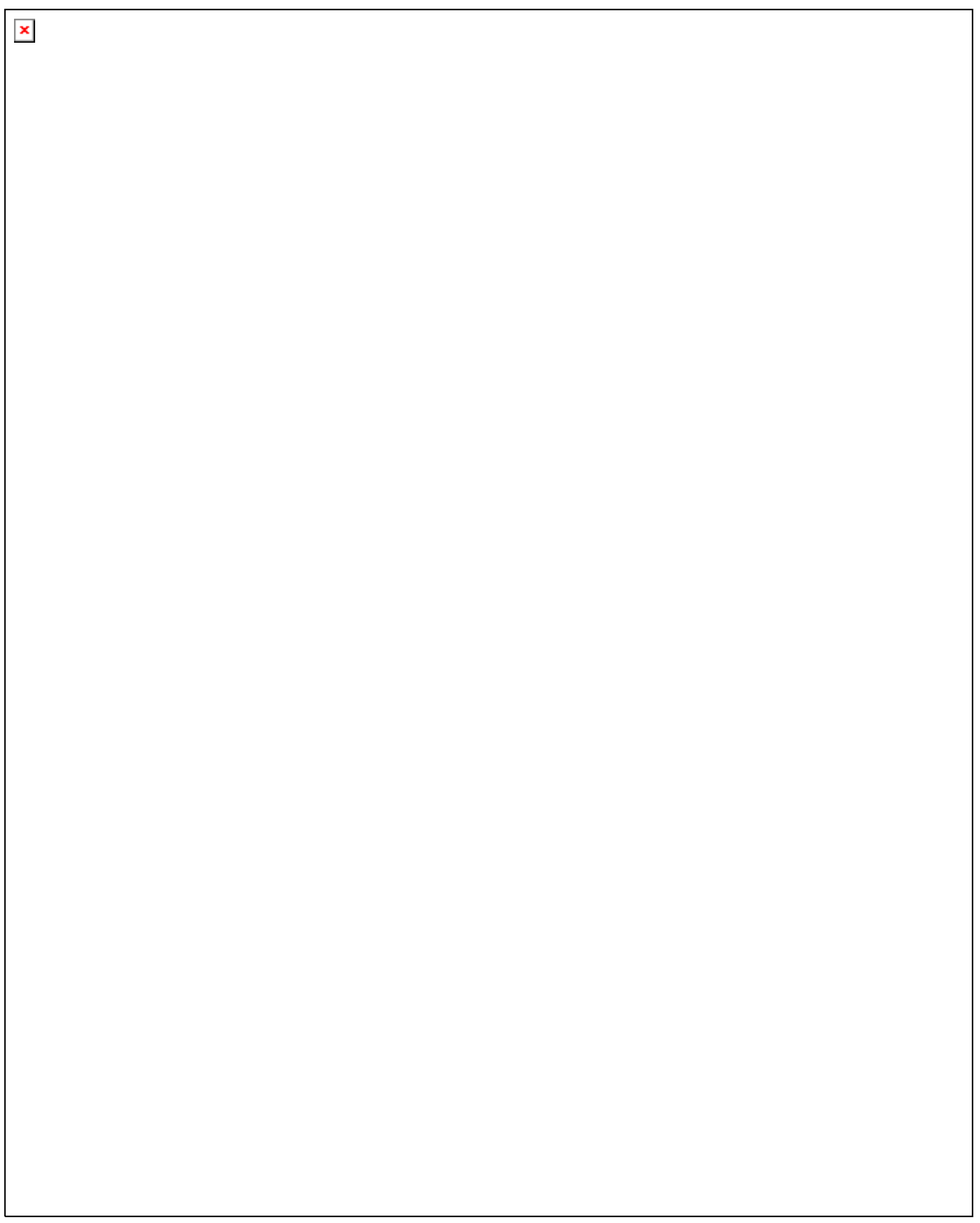




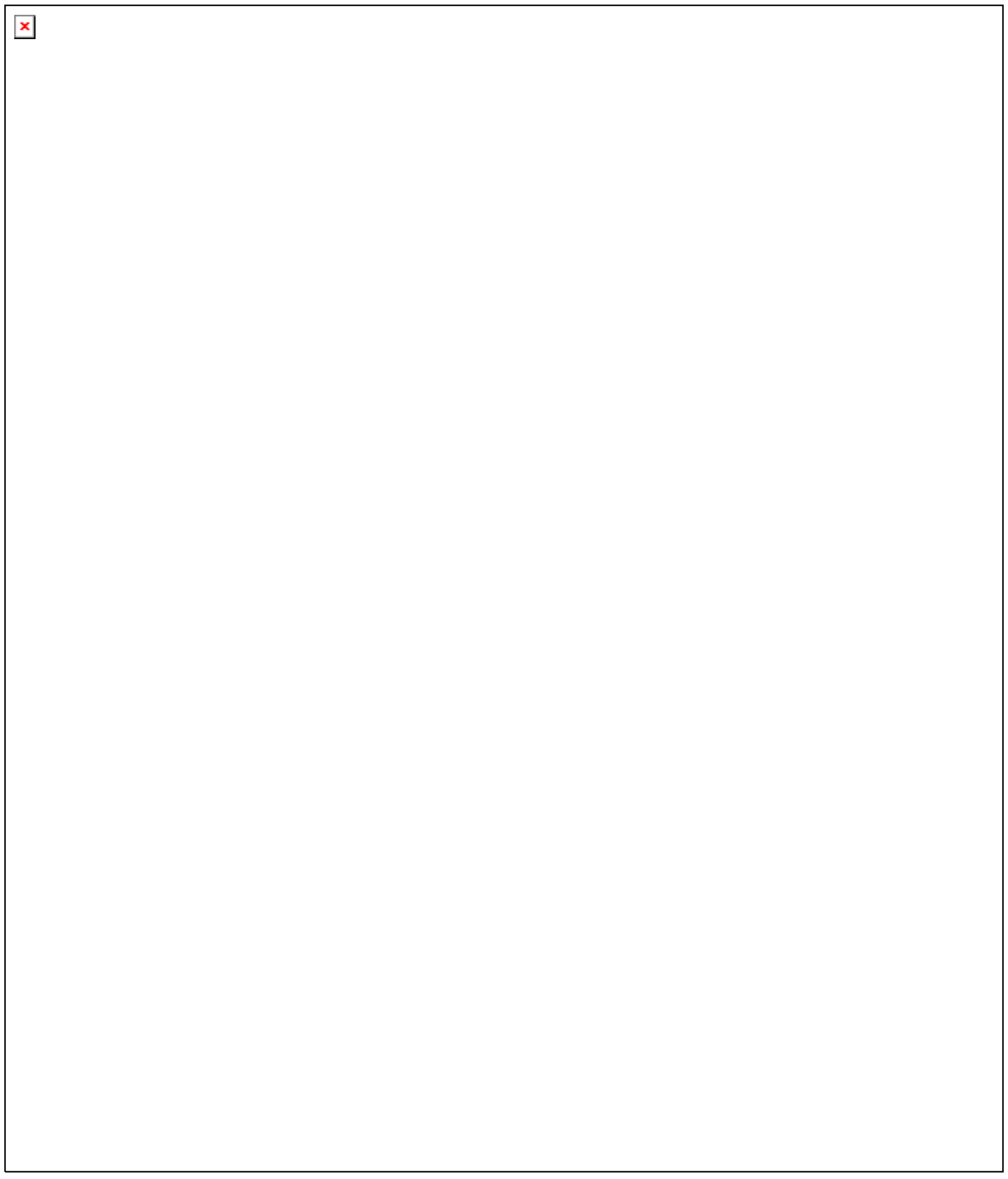




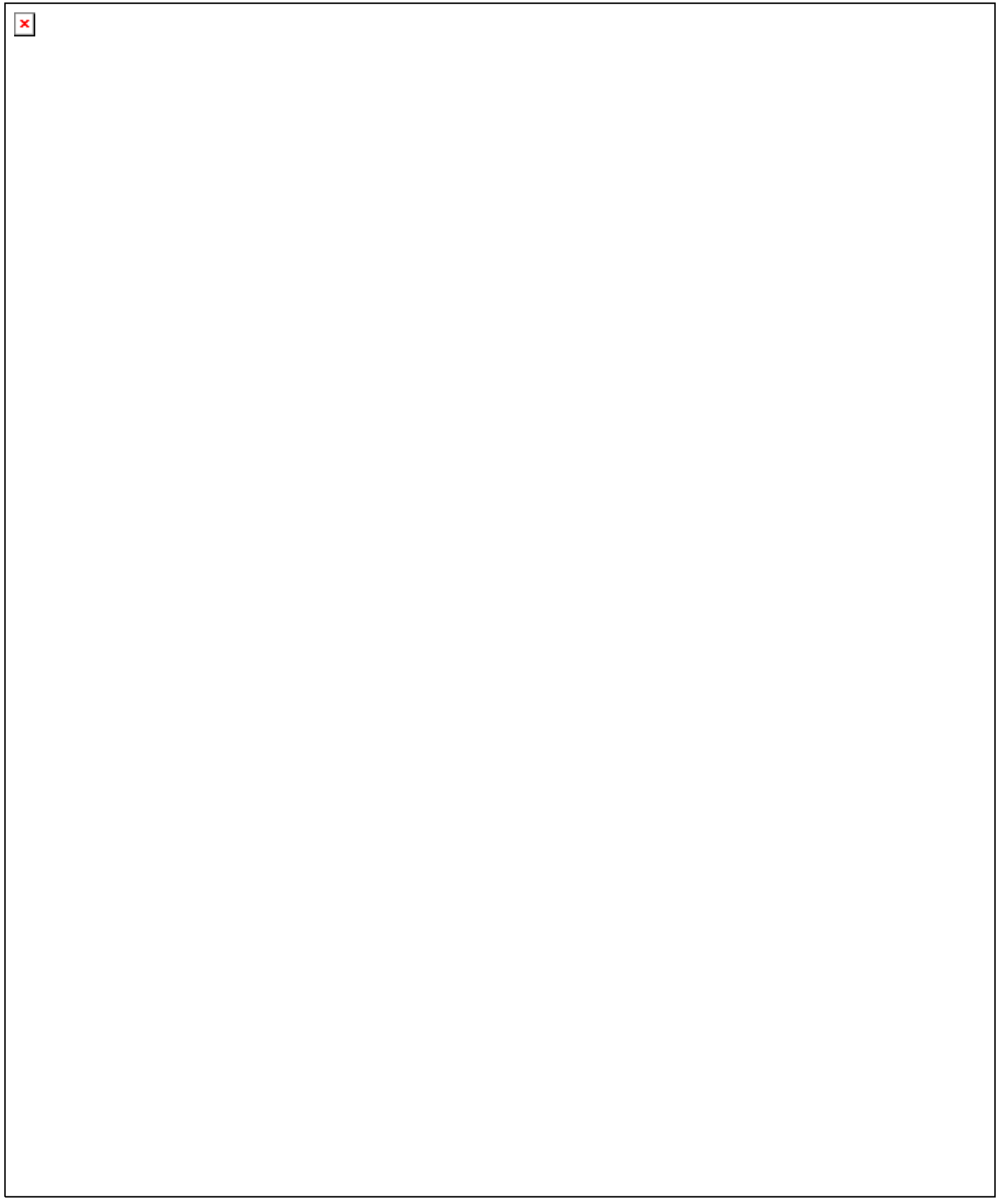


$\mathrm{x}$ 


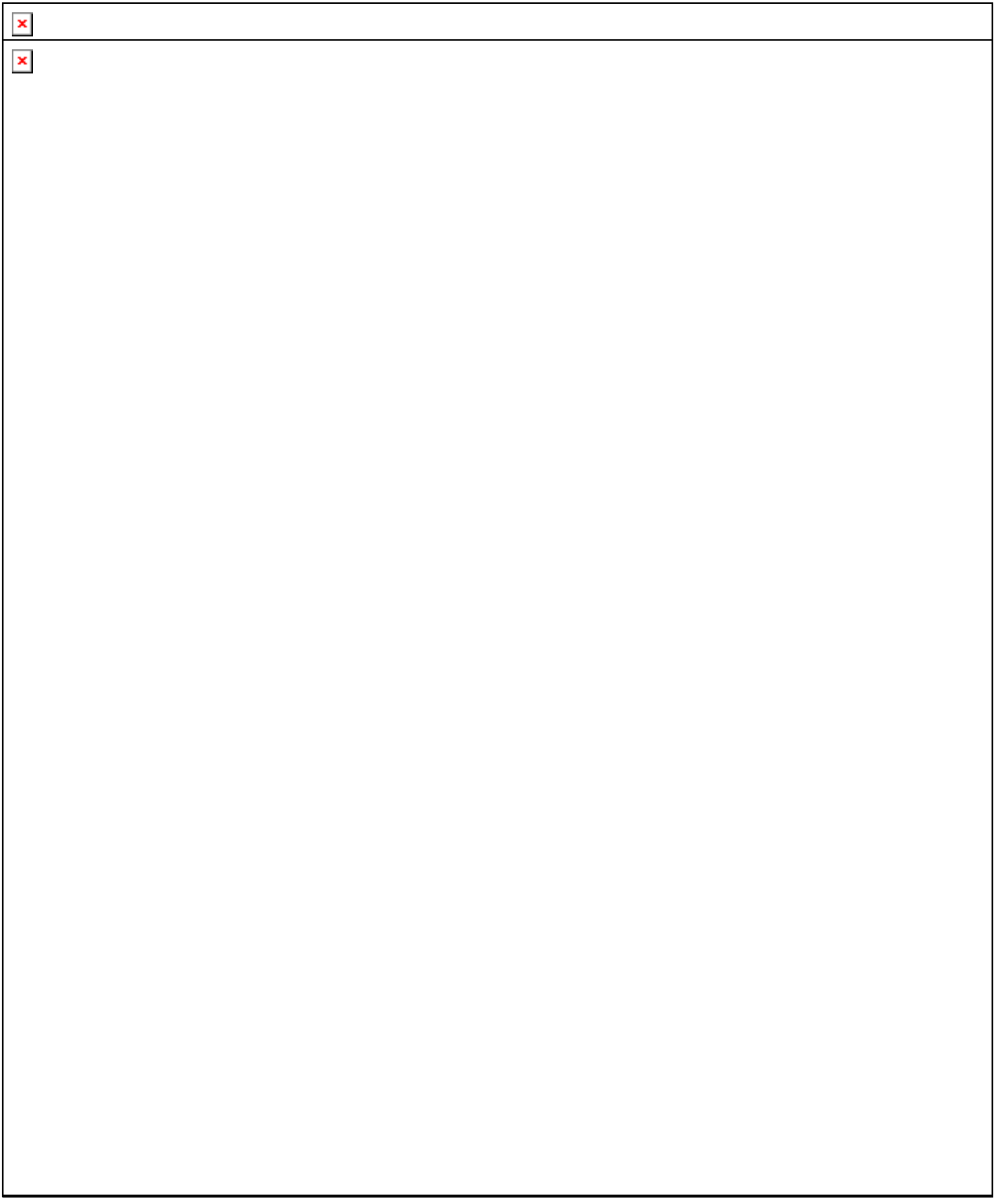




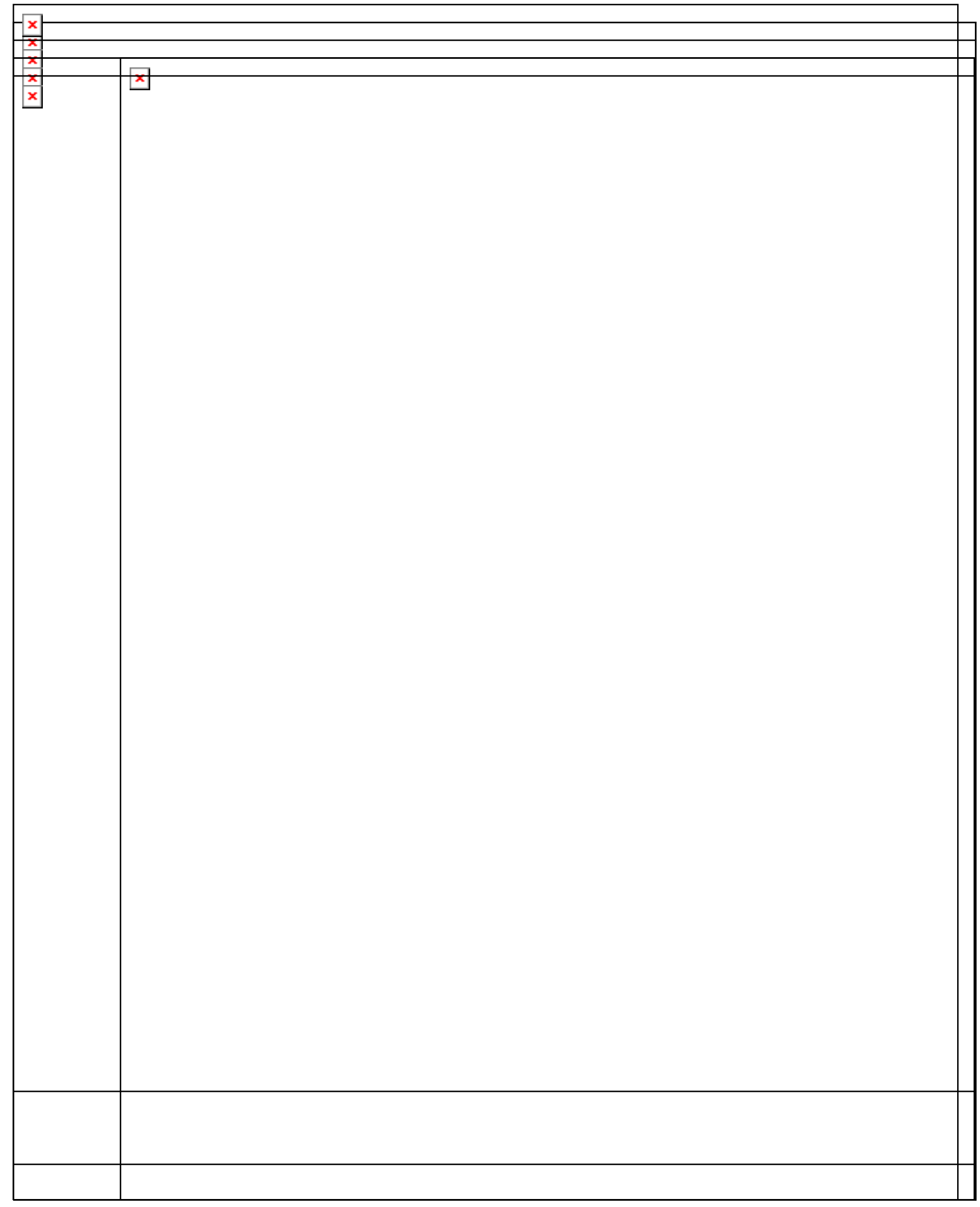




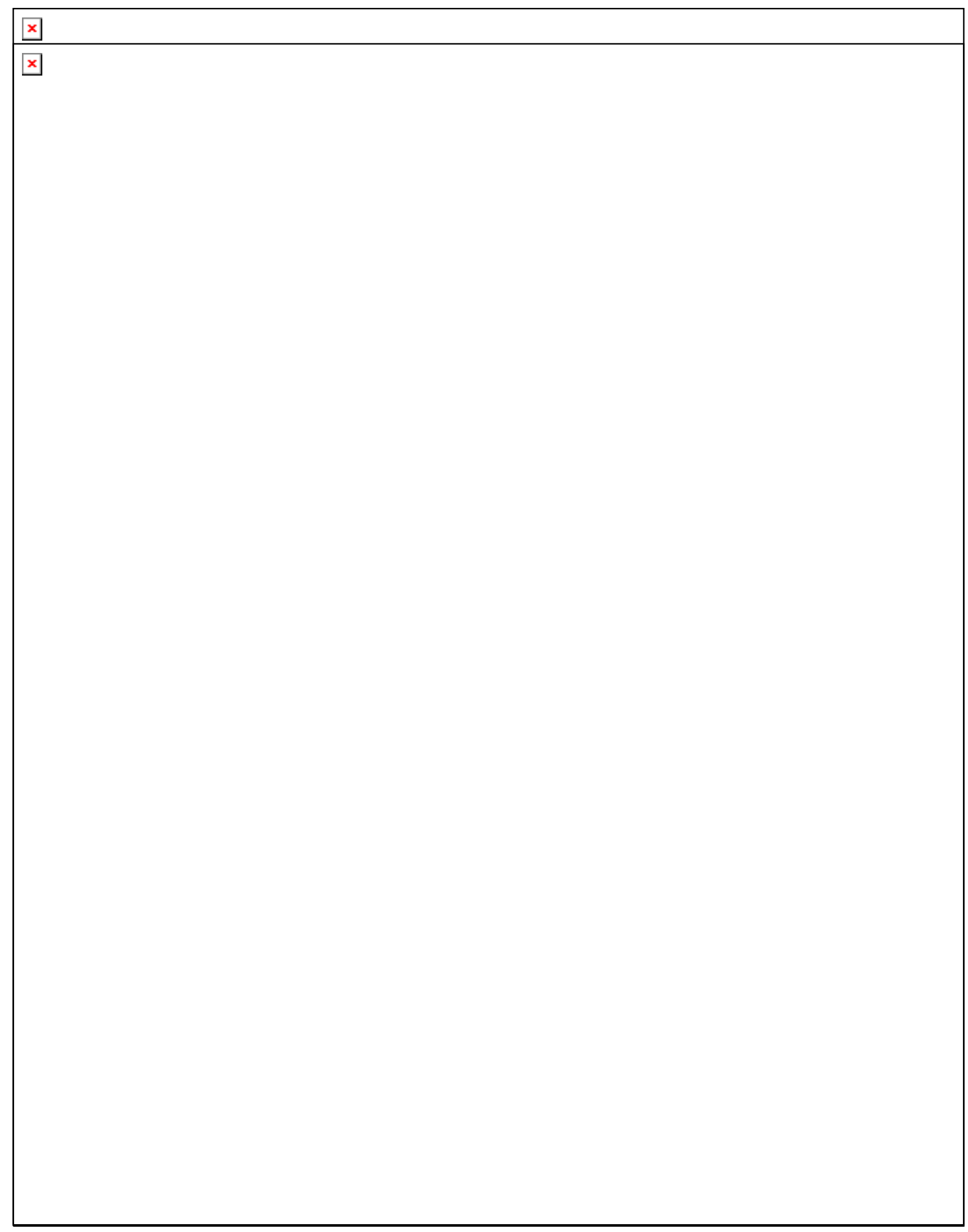




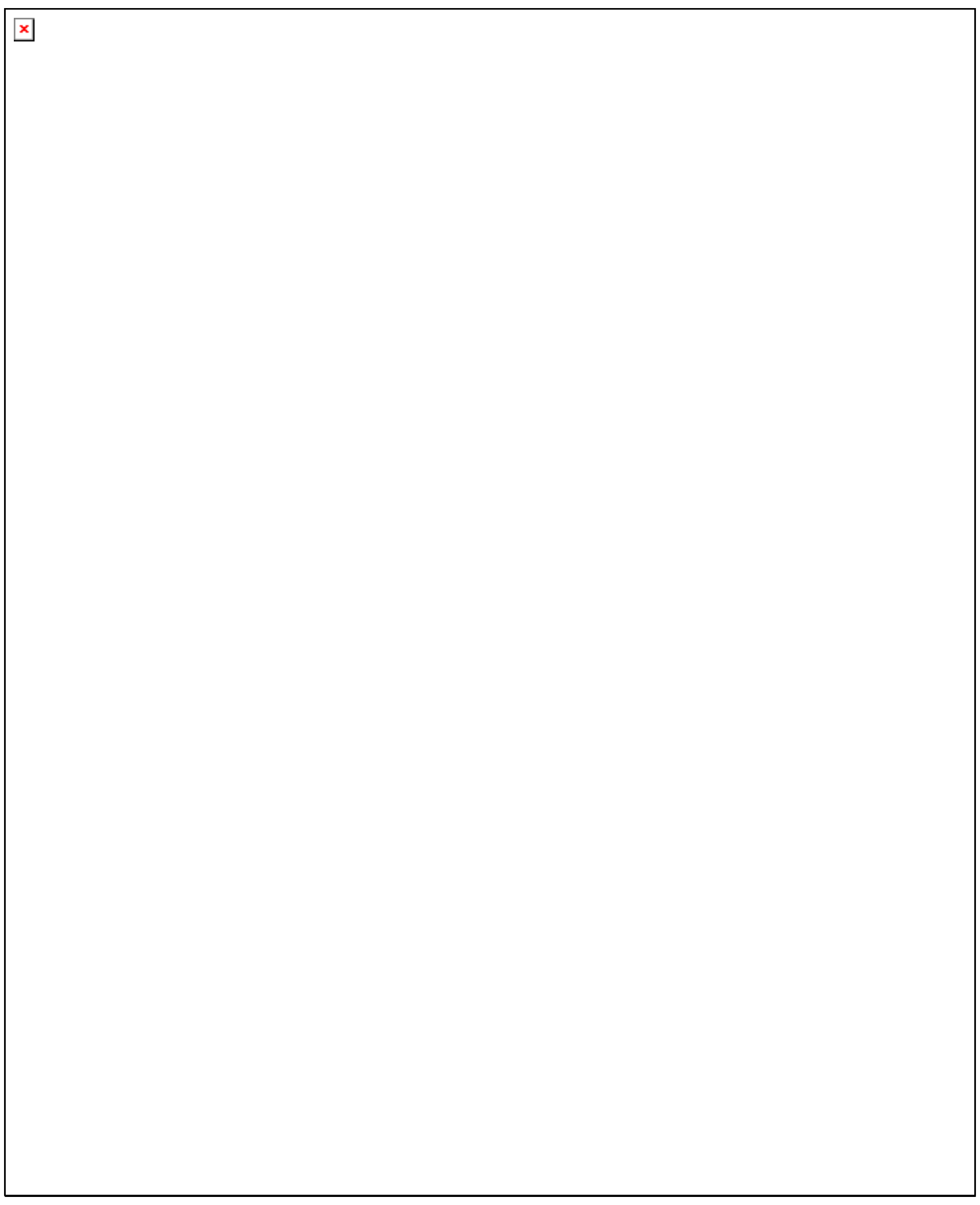

